Universidad de Lima

Escuela de Posgrado

Maestría en Derecho Empresarial

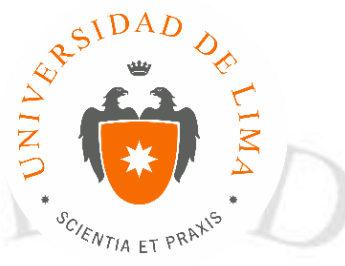

\title{
GRUPOS DE EMPRESAS
}

Trabajo de investigación para optar el Grado Académico de Maestro en

Derecho Empresarial

Martha Lourdes Victoria Chirinos Huaco

Código 19954411

Lima - Perú

Marzo del 2016 


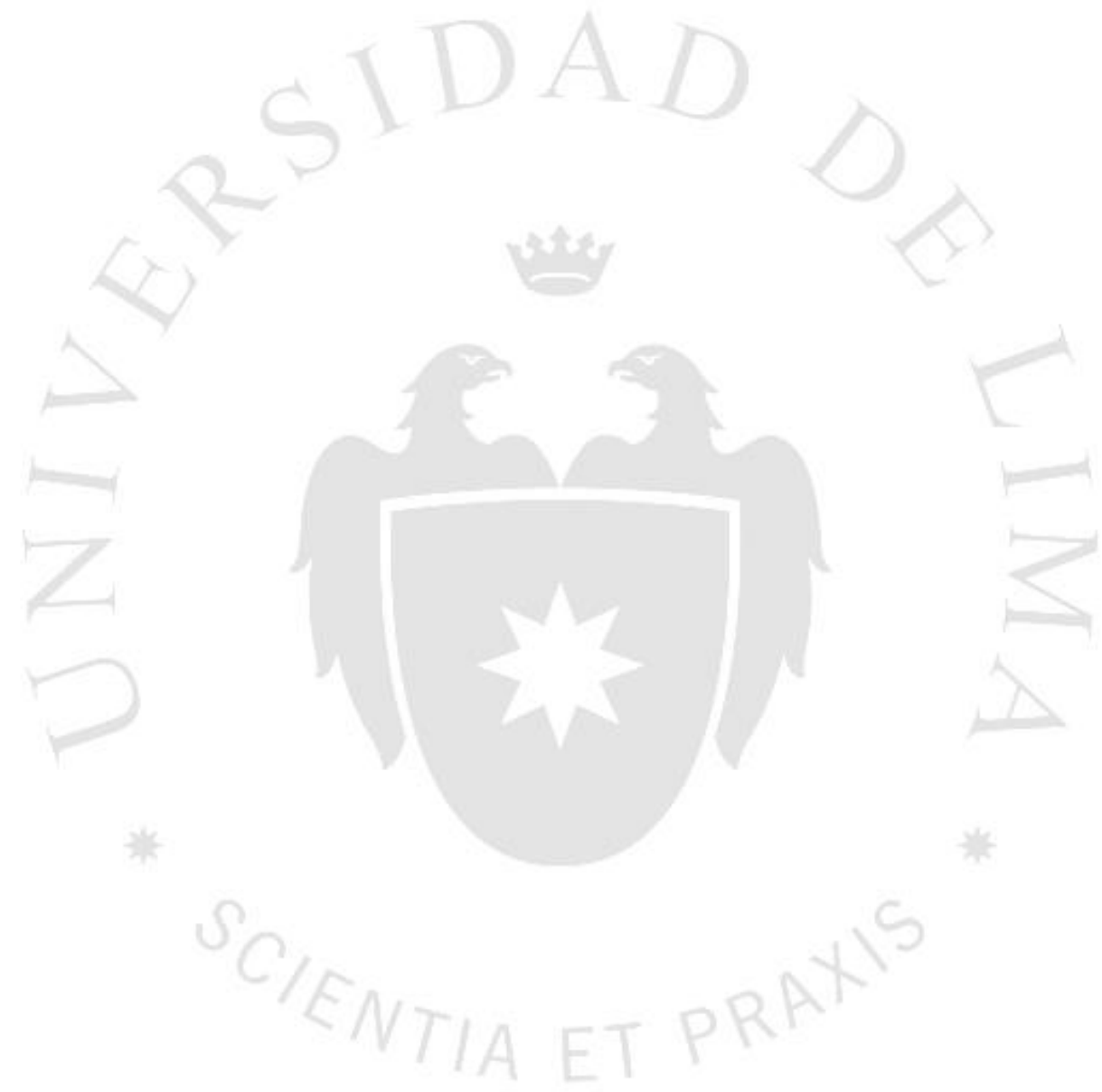




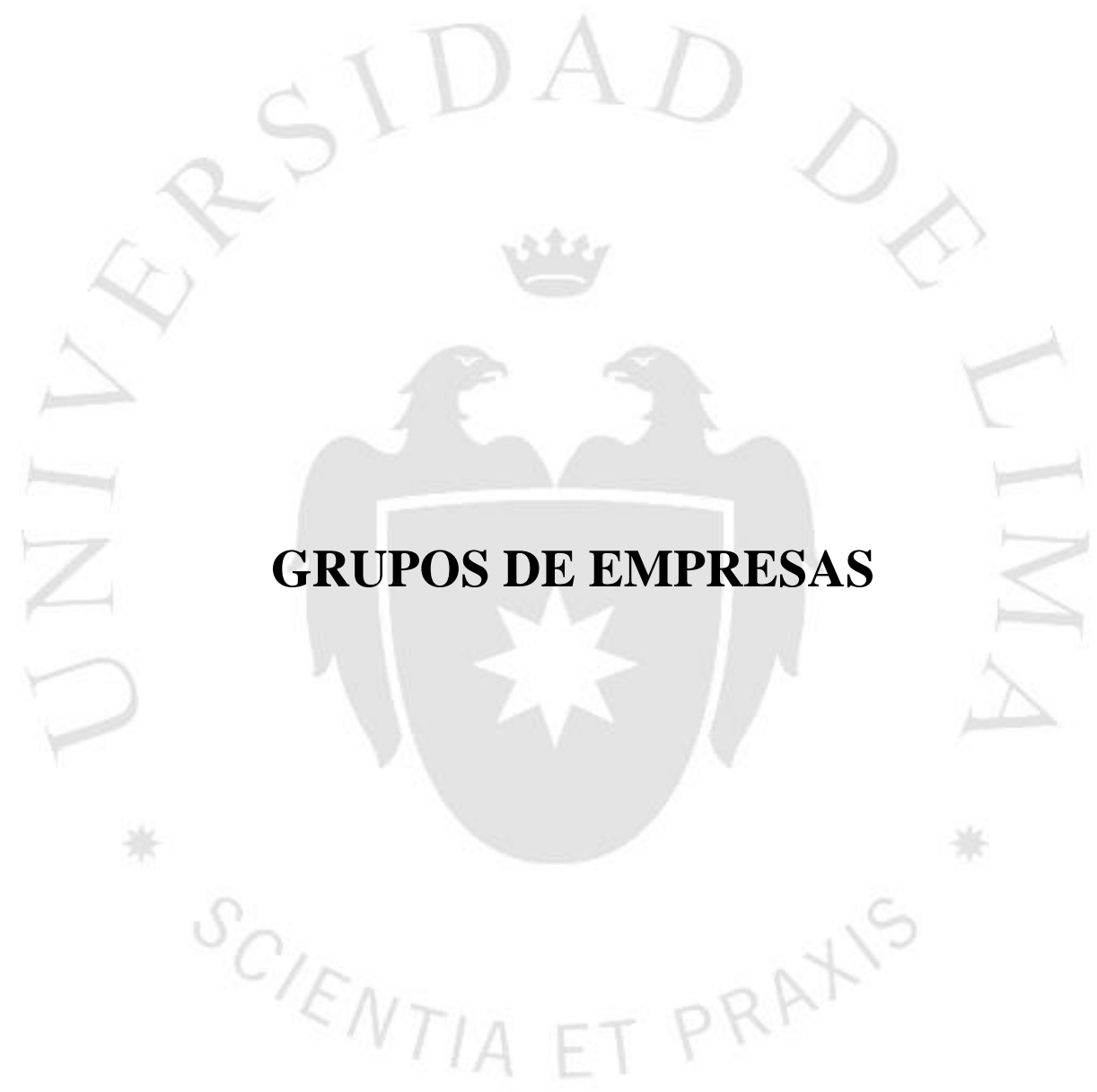




\section{TABLA DE CONTENIDO}

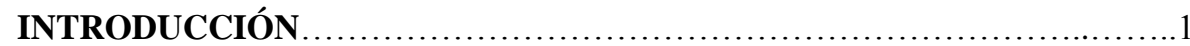

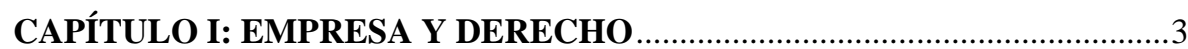

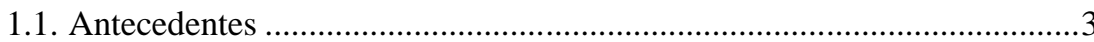

1.2. La empresa en la Constitución Política del Perú ..........................................

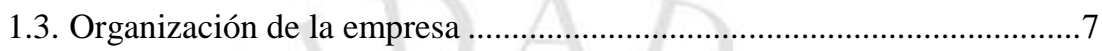

1.3.1 Formas de organización empresarial ....................................................

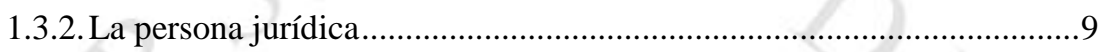

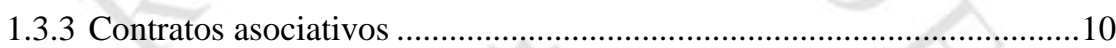

1.4. El fenómeno de la informalidad ...............................................................11

CAPÍTULO II: CONCENTRACIÓN EMPRESARIAL ……………....................12

2.1. Principales modalidades de concentración empresarial: ..............................13

2.1.1. Con pérdida de personería jurídica: .......................................................13

2.1.2. Sin pérdida de personería jurídica............................................................14

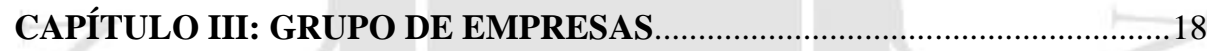

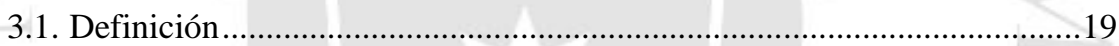

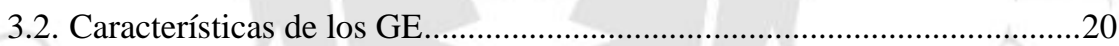

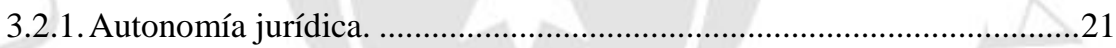

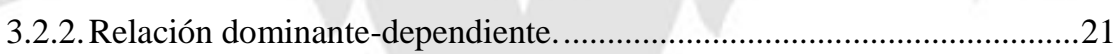

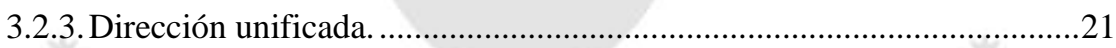

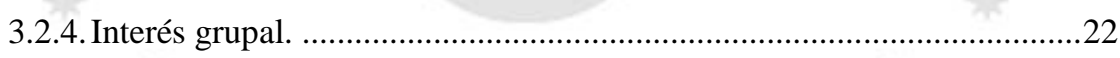

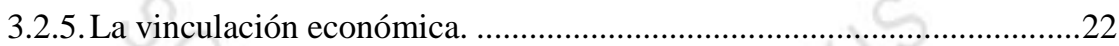

CAPÍTULO IV: PROBLEMÁtiCA DE LOS GRUPOS DE EMPRESAS -

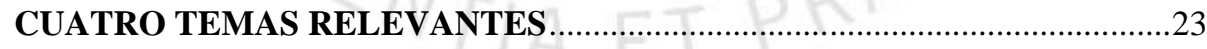

4.1. El interés grupal del GE frente al interés social de cada empresa..............23

4.2. Adopción de igual o semejante denominación o razón social ....................26

4.3. Socio minoritario de una empresa conformante de un GE..........................27

4.4. Derechos laborales de los trabajadores en un GE ......................................28

CAPÍTULO V: ANÁLISIS SOBRE LA NECESIDAD DE APROBAR LA LEY

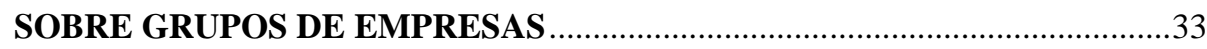

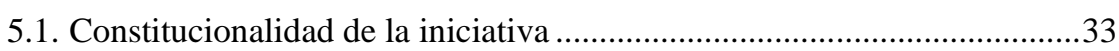


5.2. Marco legal vigente vinculado con los GE .33

5.2.1.Los grupos de empresas en el derecho societario .................................33

5.2.2. Los grupos de empresas en el derecho de mercado de valores ................36

5.2.3. Los grupos de empresas en el derecho bancario y financiero..................36

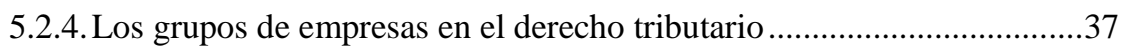

5.2.5. Los grupos de empresas en la legislación referida a MYPES .................39

5.3. Proyectos de Ley en el Congreso de la República ...................................40

5.4. Reflexiones sobre la dación de una ley sobre grupos de empresas. ...........411

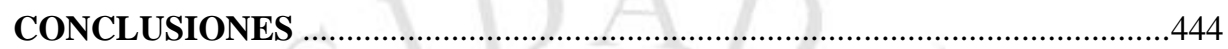

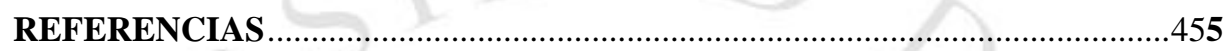

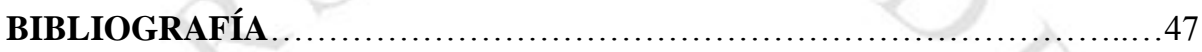




\section{ÍNDICE DE TABLAS}

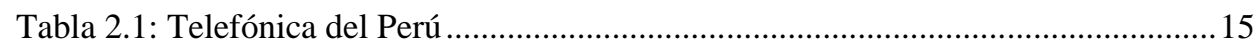

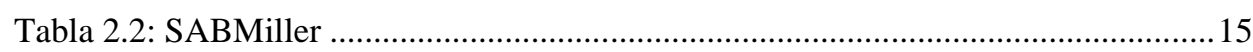

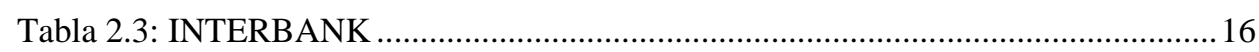




\section{INTRODUCCIÓN}

El auge de la economía de mercado, la globalización y el libre comercio, fortalecidos por la eliminación de barreras al ingreso de nuevas tecnologías, traen aparejado aumento en la producción, acceso a grandes mercados y con ello la demanda de mayores capitales.

En ese contexto, las empresas, concebidas como ente social, jurídico y económico, desarrollan actividades que buscan la eficiencia a fin de alcanzar réditos. Asimismo, adoptan modelos de concentración empresarial. Una de sus vertientes es el denominado grupo de empresas (GE) que supone la unión de más de una empresa, sin perder su personalidad jurídica y vinculadas entre sí por un interés grupal y una dirección única.

El Régimen Económico de nuestra Constitución Política tutela los derechos indispensables para el normal desenvolvimiento de las actividades empresariales - se trate de empresas unitarias o de grupos. La Carta Magna reconoce la libre iniciativa privada, la libertad contractual, la libre competencia y la libertad de empresa, principalmente. Si bien la normativa que trata el tema de los GE es escasa, la Ley General de Sociedades (Ley N. ${ }^{\circ} 26887,1997$ ) da pautas para su regulación al tratar lo relativo a la empresa unitaria, más en ella se reconocen vacíos que actualmente son suplidos por regulaciones de otros sectores (el bancario y el bursátil).

El estudio se propone evidenciar la problemática que representa los GE, los vacíos que- se encuentran en la legislación y estudiar la conveniencia de sistematizar las normas que se vinculan con su desenvolvimiento.

Para tal efecto, se analiza: i) Los antecedentes sobre la organización empresarial para detallar los orígenes del grupo de empresas; ii) Las leyes, normas y reglamentos que rigen las actividades de los grupos de empresas, iii) Las materias que requieren de acompañamiento legal en el desarrollo de los grupos de empresas, iv) Las condiciones de viabilidad o no de proponer una legislación específica para estos.

La investigación consta de cinco capítulos. En el primero, se describe la situación de la empresa frente al derecho, su concepción en el marco constitucional, las formas de organización empresarial y una breve descripción de estas. Asimismo, 
repasamos el concepto de persona jurídica y una nota sobre el fenómeno de la informalidad.

En el segundo capítulo, se analiza el fenómeno de la concentración empresarial, sus objetivos y fines, sus principales modalidades (con pérdida de personería jurídica y sin pérdida de personalidad jurídica). Se detallan las relaciones que se establecen, como son las de coordinación o de subordinación.

En el tercer capítulo, se presenta la teoría sobre los grupos de empresas, el marco conceptual, una definición, así como las características de los grupos de empresas: autonomía jurídica, relación dominante-dependiente, dirección unificada; así como una nota sobre el interés grupal y la vinculación económica.

En el cuarto capítulo se desarrolla algunas de las principales materias que forman parte de la problemática de los grupos de empresas, como son: el interés grupal del GE frente al interés social de cada empresa, la adopción de igual o semejante denominación o razón social y la situación del socio minoritario de una empresa conformante de un GE. Un tema adicional es el de los grupos de empresas y los trabajadores.

En el quinto capítulo se analiza la viabilidad o no de la necesidad de contar con una ley específica sobre GE. Para lo cual se evalúa el marco legal de los grupos de empresas y las propuestas de legislación presentadas al Congreso de la República. Asimismo, mis reflexiones sobre la dación de una ley sobre grupos de empresas.

Finalmente, se exponen las principales conclusiones del estudio sobre la base de las evidencias encontradas en la investigación. 


\section{CAPÍTULO I: EMPRESA Y DERECHO}

\subsection{Antecedentes}

La empresa como unidad económica y social juega un rol protagónico en el desarrollo de la sociedad. Esta entidad tiene también una dimensión jurídica. Si bien el fin último y legítimo de la empresa es la maximización de sus utilidades (a través de la creación de valor), también es el vehículo a través del cual se satisfacen las demandas de la sociedad por bienes y servicios, y se contribuye con el fin del Estado.

El desarrollo de la actividad de la empresa trae como consecuencia que surjan relaciones, obligaciones, derechos, etc., (que vinculan a particulares y a particulares con el Estado), es decir un conjunto de fenómenos que requieren de la regulación permisiva, restrictiva, promotora, ordenadora, entre otros- del Derecho.

Dilucidar qué surge primero, si el hecho económico o la norma, promueve grandes debates que no abordaremos en la presente investigación. No obstante, resulta importante analizar la relación, entre los factores que brindan dinamismo a la actividad empresarial, y los valores que conforman el marco legal para su desarrollo.

El entorno en que la empresa lleva a cabo sus actividades exige que sus decisiones estratégicas y de gestión busquen la mayor eficiencia, que garantice menores costos, mejores tiempos de respuesta y la mayor calidad posible, a fin de asegurar su supervivencia y una mejor posición frente a la competencia.

La dimensión global de los negocios exige altos niveles a la empresa, sin importar el ámbito en que esta desarrolla sus operaciones. En efecto, consideremos que aun cuando se trate de una empresa local, de seguro alguno de sus proveedores o clientes desarrollará negocios a nivel internacional, con la posibilidad de verse afectado como resultado de efectos o crisis importadas, además de las que se produzcan por causas internas. Como ejemplos, consideremos el efecto de la subida del dólar estadounidense, la caída de precios en la China y su impacto en la economía y por consiguiente en la empresa peruana.

Las últimas décadas del siglo pasado y lo que va del presente asistimos a la consolidación de la globalización como nueva forma de operar en los mercados. El 
ingreso de nuevos actores económicos fuertes (como China, India, Brasil y los países de Europa del Este), y el avance de la tecnología, especialmente de las comunicaciones, impulsan una dinámica más rápida y de mayor flujo en el comercio mundial. Ello ha traído como consecuencia la aparición o profundización de figuras como la liberalización de los mercados y del comercio bilateral y multilateral (cuyo ejemplo más importante son los llamados tratados de libre comercio), la deslocalización de la producción o prestación de servicios (como la maquila textil o el servicio de call centers, por ejemplo), y otras medidas que los propios Estados llevan a cabo a fin de promover su producción.

Frente a ello, cabe considerar que "las empresas existen y operan en un entorno en el que las relaciones con varios actores son cada vez más importantes" (Strandberg, 2010, p.23).

Por lo cual, la empresa debe adaptarse a su entorno creando nuevos modelos. Muestra de ello es el fenómeno de la concentración económica "que surge como consecuencia de la expansión de las grandes empresas, impulsadas por el desarrollo tecnológico, los adelantos en el transporte de carga y de pasajeros, de las comunicaciones y el deseo de conquistar nuevos mercados ante la eliminación de los límites geográficos debido a la globalización de la economía" (Hundskopf, 1998, p. XIX). En la mayoría de casos, crece la industria, aumenta la producción y se produce ampliación de horizontes, especialmente en el sector empresarial.

\subsection{La empresa en la Constitución Política del Perú}

Nuestra Carta Magna regula constitucionalmente las relaciones generadas del desarrollo de la actividad empresarial en el denominado Régimen Económico.

Dentro de las instituciones que conforman el Derecho Constitucional contemporáneo destaca la denominada Constitución Económica, concepto que tiene sus orígenes en Alemania y que permite la introducción de variables económicas que requieren atención en el quehacer nacional, y que se preocupa por el rol de Estado y de los demás agentes económicos. En la doctrina nacional, Chanamé Orbe (2009), analiza los distintos enfoques adoptados en nuestros textos constitucionales. Este autor advierte que a lo largo de nuestra historia constitucional se han ido adoptando y actualizando diversos principios que buscan armonizar el régimen económico y el político, tendiéndose a la 
protección del interés social, lo que se materializa en considerar el rol subsidiario del

Estado (p. 260)

Sobre nuestra actual Constitución Política, Chanamé Orbe (2015) sostiene que:

La vida del Estado en base al actual modelo de Economía Social de Mercado de la Constitución peruana se ha forjado de una combinación adecuada que proviene de la búsqueda de un modelo concreto que pueda ser aplicado directamente en la dinámica práctica y que otorgue garantías tanto a la empresa privada como a la sociedad en sí. (p.

45).

El Capítulo denominado Régimen Económico de la Constitución Política contempla como principales materias a la libertad a la iniciativa privada y la economía social de mercado (artículo 58) ${ }^{1}$; al principio de subsidiariedad, antes mencionado (artículo 60)², a la libre competencia (artículo 61) ${ }^{3}$, a la libertad de contratación (artículo 62) ${ }^{4}$, las

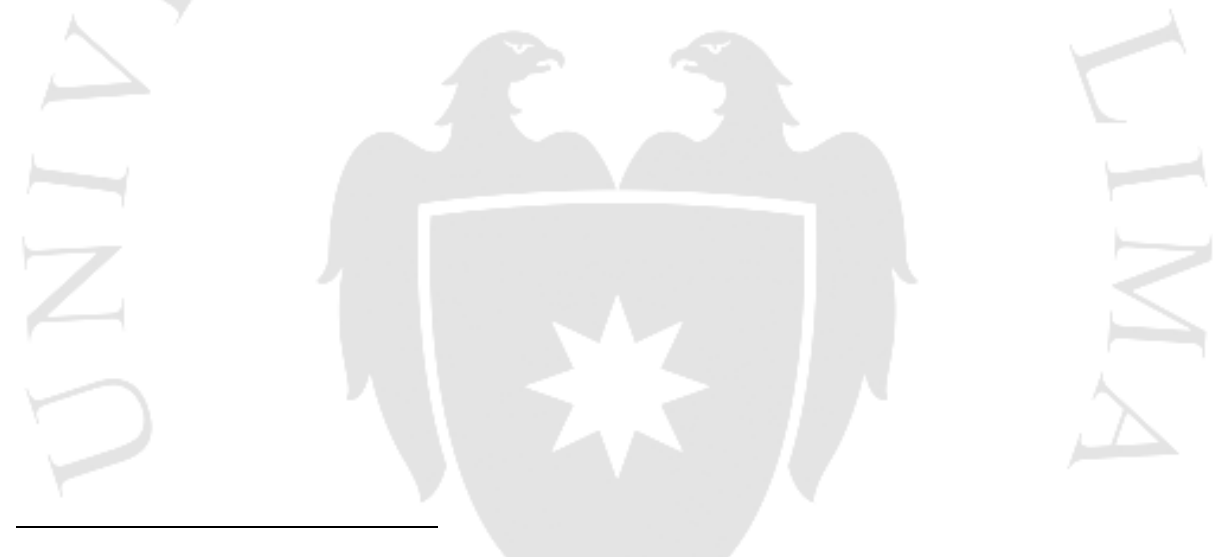

${ }^{1}$ Artículo $\mathbf{5 8}^{\circ}$. - La iniciativa privada es libre. Se ejerce en una economía social de mercado. Bajo este régimen, el Estado orienta el desarrollo del país, y actúa principalmente en las áreas de promoción de empleo, salud, educación, seguridad, servicios públicos e infraestructura.

${ }^{2}$ Artículo 60 ${ }^{\circ}$. El Estado reconoce el pluralismo económico. La economía nacional se sustenta en la coexistencia de diversas formas de propiedad y de empresa. Sólo autorizado por ley expresa, el Estado puede realizar subsidiariamente actividad empresarial, directa o indirecta, por razón de alto interés público o de manifiesta conveniencia nacional.

La actividad empresarial, pública o no pública, recibe el mismo tratamiento legal.

${ }^{3}$ Artículo $61^{\circ}$. - El Estado facilita y vigila la libre competencia. Combate toda práctica que la limite y el abuso de posiciones dominantes o monopólicas. Ninguna ley ni concertación puede autorizar ni establecer monopolios. La prensa, la radio, la televisión y los demás medios de expresión y comunicación social; y, en general, las empresas, los bienes y servicios relacionados con la libertad de expresión y de comunicación, no pueden ser objeto de exclusividad, monopolio ni acaparamiento, directa ni indirectamente, por parte del Estado ni de particulares.

${ }^{4}$ Artículo 62 ${ }^{\circ}$. - La libertad de contratar garantiza que las partes pueden pactar válidamente según las normas vigentes al tiempo del contrato. Los términos contractuales no pueden ser modificados por leyes u otras disposiciones de cualquier clase. Los conflictos derivados de la relación contractual sólo se solucionan en la vía arbitral o en la judicial, según los mecanismos de protección previstos en el contrato o contemplados en la ley.

Mediante contratos-ley, el Estado puede establecer garantías y otorgar seguridades. No pueden ser modificados legislativamente, sin perjuicio de la protección a que se refiere el párrafo precedente. 
garantías a la propiedad (artículo 63) $)^{5}$ y especialmente, la libertad de empresa (artículo $59)^{6}$.

El marco legal constitucional de la actividad empresarial reviste la mayor importancia, por cuanto permite y facilita el desarrollo económico del país, al establecer los principios fundamentales que sirven de plataforma para el funcionamiento de la economía. Como en cualquier regulación, la norma no es estática, sino que se va aproximando a la dinámica propia de cada actividad.

No obstante, sobre este Capítulo se han formulado diversas propuestas de reforma constitucional, que no han prosperado porque se ha considerado que las normas existentes han permitido desarrollar la economía del país. Flores Polo (1993) así lo reconoce al señalar que "no pueden haber inversiones ni crecimiento empresarial si las reglas de juego no son claras, transparentes y permanentes en el tiempo y en el espacio" (párr. 8).

Complementariamente, resulta relevante referirnos a algunos pronunciamientos que sobre la materia ha emitido el Tribunal Constitucional. Así en su sentencia 30302004-PA, ha definido algunas instituciones que interesan para nuestra investigación, y son:

- Empresa: "la expresión 'empresa' alude a una actividad económica organizada para los fines de la producción o el cambio de bienes y servicios y entre sus elementos constitutivos se considera a la organización y la dirección, a los cuales se suman los bienes, el capital y el trabajo".

- Libertad de empresa: "La libertad de empresa se manifiesta como el derecho de las personas a elegir libremente la actividad ocupacional o profesional que

\footnotetext{
${ }^{5}$ Artículo $6^{\circ}$. - La inversión nacional y la extranjera se sujetan a las mismas condiciones. La producción de bienes y servicios y el comercio exterior son libres.

Si otro país o países adoptan medidas proteccionistas o discriminatorias que perjudiquen el interés nacional, el Estado puede, en defensa de éste, adoptar medidas análogas. En todo contrato del Estado y de las personas de derecho público con extranjeros domiciliados consta el sometimiento de éstos a las leyes y órganos jurisdiccionales de la República y su renuncia a toda reclamación diplomática. Pueden ser exceptuados de la jurisdicción nacional los contratos de carácter financiero.

El Estado y las demás personas de derecho público pueden someter las controversias derivadas de relación contractual a tribunales constituidos en virtud de tratados en vigor. Pueden también someterlas a arbitraje nacional o internacional, en la forma en que lo disponga la ley.

${ }^{6}$ Artículo 59 ${ }^{\circ}$. El Estado estimula la creación de riqueza y garantiza la libertad de trabajo y la libertad de empresa, comercio e industria. El ejercicio de estas libertades no debe ser lesivo a la moral, ni a la salud, ni a la seguridad pública. El Estado brinda oportunidades de superación a los sectores que sufren cualquier desigualdad; en tal sentido, promueve las pequeñas empresas en todas sus modalidades.
} 
desee o prefiera desempeñar, disfrutando de su rendimiento económico y satisfacción espiritual”.

En cuanto al contenido de la libertad de empresa, basándose en la obra de Kresalja Rosselló (2004), el Tribunal ha señalado que "está determinada por cuatro tipos de libertades:

- La libertad de creación de empresa y de acceso al mercado, que significa libertad para emprender actividades económicas, en el sentido de libre fundación de empresas y concurrencia al mercado.

- La libertad de organización que contiene la libre elección del objeto, nombre, domicilio, tipo de empresa o de sociedad mercantil, facultades a los administradores, políticas de precios, créditos y seguros, contratación de personal y política publicitaria, entre otros).

- La libertad de competencia.

- La libertad para cesar las actividades es la libertad de disponer el cierre o cesación de las actividades de la empresa creada cuando lo considere más oportuno". (p. 549)

En síntesis, este es el marco constitucional, del cual derivan leyes que desarrollan las instituciones económicas y señalas las pautas vinculadas a la actividad empresarial.

\subsection{Organización de la empresa}

La sola idea de hacer empresa o de "emprender" un negocio implica un conjunto de decisiones sobre cómo organizar el proyecto, a fin de lograr los objetivos empresariales que se busca alcanzar. Se puede ingresar al campo empresarial desde diversas modalidades, algunas más rigurosas que otras en cuanto a la forma, dependiendo del tipo de actividad y de la escala empresarial. En este punto nos debemos referir a los siguientes conceptos:

\subsubsection{Formas de organización empresarial}


Para iniciar actividad comercial en nuestro país, una persona o un grupo de personas naturales o jurídicas, con una idea de negocio, pueden optar por desarrollarla en forma individual o en sociedad.

\section{- Formas unipersonales:}

En el Perú se reconocen dos formas de emprendimiento unipersonal: la empresa unipersonal (EU) y la Empresa Individual de Responsabilidad Limitada (EIRL).

a) EU: Su principal característica es que no constituye una persona jurídica distinta al titular del negocio. Responde ilimitada y personalmente por las obligaciones con todo su patrimonio. En sentido amplio, se "formaliza" mediante su inscripción en el Registro Único de Contribuyentes (como persona natural con negocio). Desde este acto responde por los tributos que le corresponda frente a la Administración Tributaria.

b) EIRL: Regulada por el Decreto Ley 21621, Ley de la Empresa Individual de Responsabilidad Limitada. En el citado dispositivo se estipula los requisitos para su constitución y funcionamiento, estableciéndose que sólo pueden constituir y ser titulares de esta, las personas naturales. Tiene patrimonio propio, por lo que la responsabilidad del titular está limitada a los aportes hechos a la empresa. Este no asume personalmente las obligaciones de la EIRL, salvo excepciones, como las que señala el artículo 40 del citado Decreto Ley, y que se refiere a los casos en que i) la empresa no esté debidamente representada; ii) se han efectuado retiros sin la justificación adecuada, y, iii) si producida la pérdida del 50\% o más del capital no se hubiese compensado o disminuido el mismo.

Como se ha señalado, para adquirir personería jurídica es necesario que la constitución conste en escritura pública y que sea inscrita en los registros públicos correspondientes. El titular tiene a su cargo la decisión sobre los bienes y actividades de la empresa y la gerencia es la encargada de la administración general. El titular puede desempeñar la gerencia.

Como se puede advertir, en el primer caso la responsabilidad por las obligaciones del negocio será asumida en forma personal e ilimitada por el 
titular del negocio unipersonal. Caso distinto es el de la EIRL que tiene el límite del aporte.

\section{- Formas societarias:}

Optar por una forma societaria supone pluralidad de integrantes, y su organización se sujeta a las figuras reguladas en la Ley General de Sociedades. La elección o no de algún tipo societario estará en función de la decisión que se tome respecto al nivel de responsabilidad de los socios (limitada o ilimitada); del tipo de accionariado (difundido o no entre el público), o si se desea establecer restricciones a la libre transferencia de acciones, entre otros.

En caso de no completar los trámites legales de constitución de una sociedad se da origen a una sociedad de hecho, con las implicancias jurídicas que esto acarrea, y que supone que su representante tiene la misma responsabilidad ante la Administración Tributaria que una empresa constituida.

La forma societaria de mayor aceptación es la sociedad anónima (SA), que en nuestra legislación tiene dos modalidades: la sociedad anónima cerrada (SAC) y la sociedad anónima abierta (SAA).

\subsubsection{La Persona Jurídica}

La persona jurídica es una creación del derecho, por la cual un ente jurídico diferente de la persona o personas naturales que la conforman, es sujeto de derechos y de obligaciones, hasta su extinción. Tiene voluntad propia y un patrimonio distinto del de sus socios, administradores o representantes.

En doctrina, al revisar la teoría sobre la persona jurídica, se encuentra múltiples estudios, pero a nuestra investigación le interesa señalar que la personalidad jurídica de una empresa tiene similares efectos que la personalidad física, tan es así que la ley regula lo pertinente sobre su nombre (denominación social o razón social), su domicilio, su patrimonio, su objeto social, su duración, entre otros. Esta se adquiere, al inscribirse en el Registro pertinente y será la inscripción de su extinción la que la desaparezca. Así lo dispone el artículo 6 de la Ley 26887, Ley General de Sociedades (en adelante LGS). 


\subsubsection{Contratos asociativos}

Además de las formas societarias descritas, es bastante frecuente que dentro del mundo empresarial se consideren los contratos asociativos. La Ley General de Sociedades (LGS) los recoge en su Libro Quinto, específicamente en el artículo 438 que dispone: "Se considera contrato asociativo aquel que crea y regula relaciones de participación e integración en negocios o empresas determinadas, en interés común de los intervinientes. El contrato asociativo no genera una persona jurídica, debe constar por escrito y no está sujeto a inscripción en el Registro".

Modalidades:

\section{i) Asociación en Participación}

La Asociación en Participación resulta de un acuerdo entre dos o más personas naturales o jurídicas, con el objeto de realizar un proyecto. No genera la creación de una persona jurídica más, distinta a la de sus conformantes. No tiene una razón social ni una denominación especial.

Participan en este contrato el asociante, como responsable ante terceros por los actos de la asociación, quien asume la administración, a título personal; de otro lado, el asociado, que aporta bienes o servicios y es responsable solo hasta el monto de su aporte. No participa de la administración del negocio, pero si tiene derecho a la rendición de cuentas y distribución de utilidades.

ii) Consorcio

Nuestra LGS lo contempla en el artículo 445. Por medio de este contrato dos o más personas - se entiende que naturales o jurídicas - se asocian para emprender un negocio participando en él activa y directamente y sin perder su autonomía. Según el contrato existe la obligación de efectuar determinadas actividades para luego responder por ellas. Igualmente, si las partes aportan bienes estos les siguen perteneciendo en exclusividad. Habrá copropiedad si es que durante la vigencia del contrato se adquieren bienes.

En el contrato se pacta la forma cómo se reparten las utilidades o las pérdidas. La responsabilidad frente a terceros es solidaria si así lo dice el contrato o lo dispone la Ley. 


\subsection{El fenómeno de la informalidad}

Nos hemos referido hasta este punto a las modalidades formales de organizar un emprendimiento. Sin embargo, merece la pena señalar que en nuestro país coexisten hasta tres maneras de llevar a cabo las actividades económicas: "las que se adecúan a la legislación vigente (formales); las que las incumplen de acuerdo a su conveniencia (informales); y aquellas que abiertamente desafían toda ley y principio ético (delictivas)" (Durand, 2013, p. 22). Cada una de ellas constituyen economías con sus propias características que incorporan en su quehacer a sus agentes (dueños, inversionistas y trabajadores). Conviven bajo los parámetros estatales y originan repercusiones en la economía.

Si bien los analistas consideran que muchas son las causas que originan este fenómeno, se debe tener en cuenta que pertenecer al sector informal supone estar al margen de las cargas tributarias y demás normas legales, pero también implica que sus actores no cuenten con la protección y los servicios que el Estado puede ofrecer. (Loayza, 2008). Resulta pertinente señalar que, para uno de sus principales estudiosos, el antropólogo Matos Mar (1985), el factor fundamental para el surgimiento de la informalidad en el país es la falta de presencia del Estado. 


\section{CAPÍTULO II: CONCENTRACIÓN EMPRESARIAL}

La sociedad anónima ha constituido un mecanismo importante para cubrir las necesidades y los requerimientos jurídicos y económicos de la actividad comercial e industrial en el devenir histórico, más el propio desarrollo de esta como unidad comercial no ha sido suficiente por lo que surge la agrupación de empresas como un reflejo de la concentración económica y financiera a la que se tiende en aras de fortalecerlas, controlar el riesgo y de acceder a mercados más grandes.

Para Morales Acosta (1994) la concentración empresarial es una de las manifestaciones de la propensión natural de los agentes económicos de eliminar la competencia en el mercado. Agrega que la disposición a concentrar recursos económicos es común puesto que se pretende influir decisivamente en el mercado, incrementando el poder económico y de alguna manera su poder político (p.24).

Al confirmar que la eliminación de la competencia es una de las causas de la concentración empresarial, el Informe Legal de Derecho Corporativo, sostiene: "la concentración empresarial consiste en la acumulación de medios de producción de un determinado negocio en una actividad económica" (Informe Legal Caballero Bustamante, 2009, p.11). Para Daniel Echaiz, “es un fenómeno de raíz económica y con consecuencias jurídicas, mediante el cual dos o más empresas integran sus recursos (económicos y humanos, entre otros), a efectos de conseguir un beneficio común, diferente del interés empresarial" (Echaiz, 2010, p.48).

Otro análisis, el de Villanueva Haro (2007) sostiene que es el fenómeno económico de la globalización el que permite que la empresa adquiera una nueva perspectiva, en tanto su vinculación con la sociedad a través de sus múltiples actos, alcanzando considerable crecimiento corporativo, lo que no constituye hechos aislados, sino que se encuentra incentivado por los convenios multilaterales de comercio, de inversión, entre otros factores. Considera además que la concentración empresarial ha de ser vista desde tres planos: el positivo, que brinda oportunidades de empleo, aumento en la producción, contar con socios estratégicos, entre otras características; el difuso, ya que esta práctica 
empresarial puede ser confundida y sus efectos perniciosos no resultan sencillos de determinar en un mercado cambiante; y, el negativo, que implica un abuso de posición de dominio de mercado, limitando y distorsionando la competencia, evasión fiscal, falta de respeto a los derechos laborales, fraudes de personas jurídica, entre otros.

Ante este panorama, surge la necesidad - sin que ello signifique una interferencia con el derecho constitucional de libertad de empresa ${ }^{7}$ - en el sentido de que cada integrante del grupo de interés de una empresa, sea accionista, trabajador, acreedor, entre otros, asuma una posición vigilante frente a las acciones empresariales a fin de evitar denuncias, abusos. En la idea que, por ejemplo, se pueden mejorar las políticas de competencia si es que desde los consumidores se denuncian las violaciones a sus derechos. Se trata de una ardua tarea, pero necesaria frente a la dispersión de la normativa vinculada a la materia.

\subsection{Principales modalidades de concentración empresarial:}

A raíz del fenómeno de la concentración empresarial surgen diversas formas de agruparse en función al particular interés de las empresas y su necesidad de crecimiento. Esto se ve reflejado a través del diseño de estrategias para eliminar la competencia o administrar mejor sus recursos. Lo que las induce a materializar y a aceptar entre ellas situaciones de control y de sujeción a una de ellas.

La concentración empresarial tiene dos manifestaciones, según se pierda o no la personería jurídica:

\subsubsection{Con pérdida de personería jurídica}

Las ventajas de agruparse conducen a las empresas a aceptar perder su natural autonomía en pro de mejores condiciones de negocios. Esta figura se materializa en la fusión, consagrada en el artículo $344^{8}$ de la LGS, que establece las pautas para su

\footnotetext{
${ }^{7}$ Como se ha señalado, nuestra Carta Magna "facilita y vigila" la libre competencia. Además "combate toda práctica que la limite y el abuso de posiciones dominantes o monopólicas” (artículo $61 \mathrm{CPP}$ ), permitiéndose de este modo, proteger al consumidor y brindarle la posibilidad de elegir entre diversas ofertas en el mercado sobre un mismo bien o servicio.

${ }^{8}$ Artículo 344.- Concepto y formas de fusión
} 
realización. Se refiere a los casos en que los accionistas de las empresas acuerdan constituir una nueva sociedad, para lo cual optan por su disolución, pero sin liquidación, y acuerdan también que el íntegro de su patrimonio sea transferido a una nueva empresa.

Otra modalidad de fusión se da cuando las sociedades acuerdan disolverse sin liquidarse, pero que su patrimonio sea exclusivamente transferido a una sociedad - ya existente - que es la que la o las absorbe; conociéndose esta modalidad como fusión por absorción o incorporación.

Ha sido tal la repercusión de esta figura, por las bondades que representa, que podría hablarse de un "boom" de fusiones y adquisidores, encontrándose entre las razones principales, la necesidad de obtener activos estratégicos y lograr eficiencias operativas por la generación de sinergias, tal como lo detalla Gestión, citando como fuente el Estudio de Fusiones y Adquisiciones 2015, elaborado por PWC (Gestión, 7.2.2016).

\subsubsection{Sin pérdida de personería jurídica}

Distinto es el caso en que una pluralidad de empresas ve por conveniente estrechar sus relaciones jurídicas, comerciales, etc., motivadas por un interés particular de ampliar sus beneficios y disminuir sus pérdidas actuando conjuntamente. No se trata de disolverse, ni de conformar una nueva persona jurídica, ni menos de transferir su patrimonio. Conservan su autonomía jurídica, aunque no puede decirse lo mismo de la empresarial. Para Arias Schereiber (1998) la finalidad es "establecer o fortalecer vínculos entre empresas que buscan un propósito común destinado a poner en marcha un negocio o modernizar uno que ya exista" (p. 411).

Por la fusión dos a más sociedades se reúnen para formar una sola cumpliendo los requisitos prescritos por esta ley.

Puede adoptar alguna de las siguientes formas:

a). La fusión de dos o más sociedades para constituir una nueva sociedad incorporante origina la extinción de la personalidad jurídica de las sociedades incorporadas y la transmisión en bloque, y a título universal de sus patrimonios a la nueva sociedad; o,

b). La absorción de una o más sociedades por otra sociedad existente origina la extinción de la personalidad jurídica de la sociedad o sociedades absorbidas. La sociedad absorbente asume, a título universal, y en bloque, los patrimonios de las absorbidas.

En ambos casos los socios o accionistas de las sociedades que se extinguen por la fusión reciben acciones o participaciones como accionistas o socios de la nueva sociedad o de la sociedad absorbente, en su caso. 
Para efectos de concretar la concentración no se requiere formalidad ni se aplica dispositivo legal alguno, pero si se manifiestan características que permiten identificar al grupo dentro del mercado, y estas están dadas por las relaciones que las empresas establecen entre sí. Entre estas tenemos:

a) Relaciones de coordinación.

Según se trate de empresas que mantienen un trato horizontal, entre ellas se persigue la colaboración, aunque también se distingue la cooperación y la coordinación. Tal es el caso del cártel, el consorcio, la asociación en participación y el joint venture, principalmente.

\section{b) Relaciones de subordinación.}

Son las que se establecen cuando una de las empresas ejerce dominación sobre la o las otras. Se identifica una estructura de organización vertical. Existe la voluntad en las dominadas de acatar las disposiciones y directrices de la dominante. Este caso se configura en los grupos de empresas (GE).

En esta agrupación de empresas se establecen diversos vínculos, principalmente comerciales, que dan nacimiento a un sinnúmero de relaciones tanto internas como frente a terceros, caracterizadas por su complejidad y en muchos casos, sin precedentes. Ante la ausencia de norma específica para los GE de rango legal, esta necesidad es cubierta por dispositivos infra legales en las disciplinas del derecho societario, financiero, tributario, laboral, entre otros, aunque de modo disperso y ocasional. La contribución de la doctrina y la jurisprudencia en esta materia pretende apoyar en la atención de la problemática que se presenta.

En nuestro país tenemos importantes exponentes de este fenómeno. A continuación, la conformación de algunos grupos cuyas actividades se realizan en el país:

Tabla 2.1

Telefónica del Perú

Pertenece al Grupo Económico de Telefónica, S.A., empresa española dedicada al negocio de telecomunicaciones, está conformado por:

\begin{tabular}{|c|}
\hline \multicolumn{2}{|c|}{ Empresas } \\
\hline Telefónica, S.A.; las cabeceras de Grupo de las líneas de negocio explotadas por \\
\hline
\end{tabular}


empresas locales (Telefónica, S.A., Telefónica de España S.A., Telefónica

Latinoamérica Holding S.L., Telefónica Internacional S.A. y Latin America Cellular

Holding BV, entre otras); las empresas locales controladas directa e indirectamente por Telefónica, S.A. o las sociedades indicadas (Telefónica del Perú S.A.A.,

Telefónica Gestión de Servicios Compartidos Perú S.A.C., Media Networks Latin

America S.A.C., Terra Networks Perú S.A.) y las filiales de éstas (Telefónica

Multimedia S.A.C., Servicios Globales de Telecomunicaciones S.A.C., Telefónica

Centros de Cobro S.A.C., Star Global Com S.A.C.), entre otras.

Fuente: SMV

Tabla 2.2

SABMiller

SABMiller es una compañía Anglo-Sudafricana que surgió por la fusión de South African Breweries, Miller Brewing en 2002 y Bavaria S.A. en 2005.

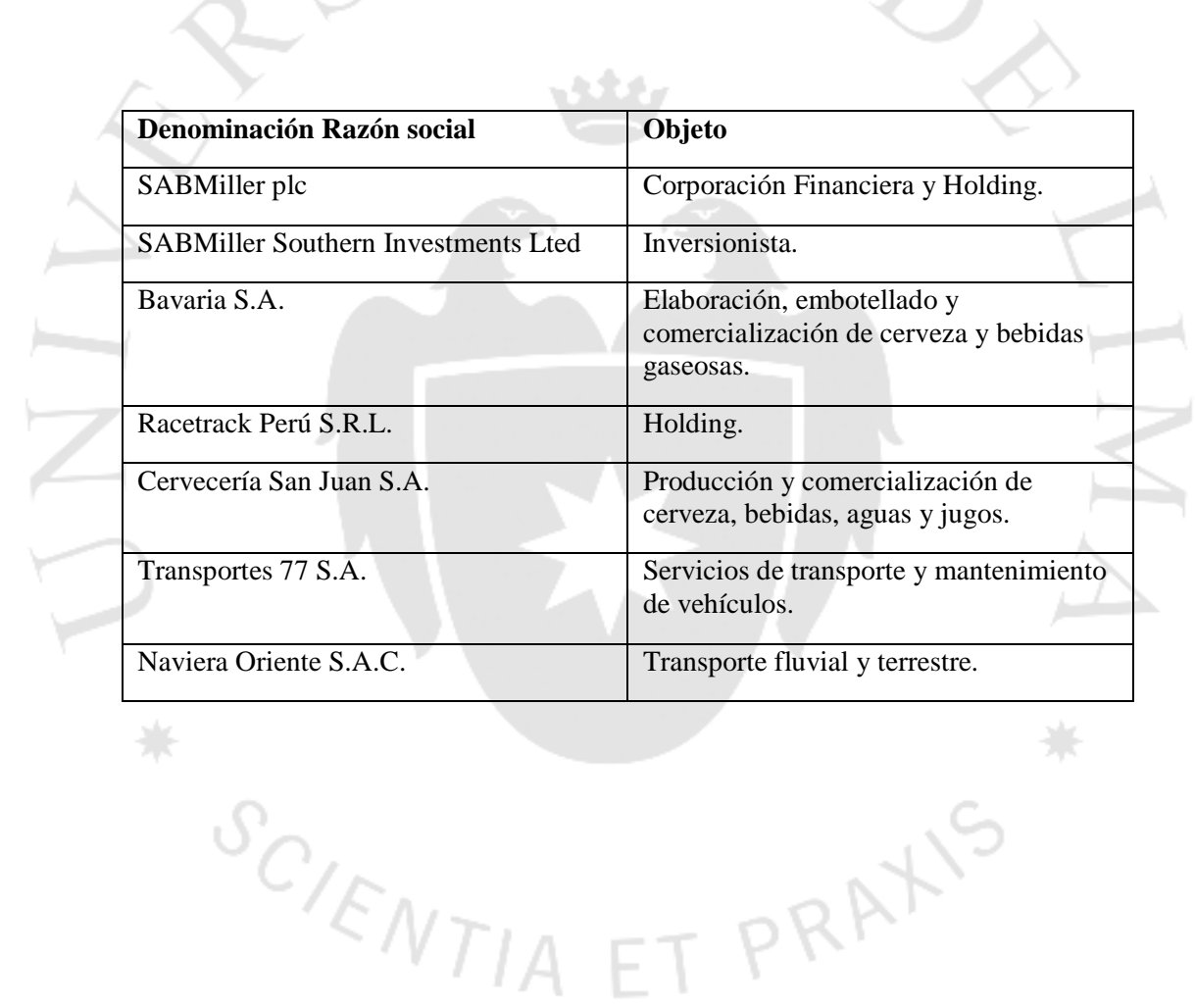


Tabla 2.3

\section{INTERBANK}

La sociedad pertenece al denominado Grupo Intercorp, cuyas principales empresas integrantes se detallan a continuación:

\begin{tabular}{|c|c|}
\hline Determinación/Razón Social & Objeto Social \\
\hline Intercorp Perú Ltd. & $\begin{array}{l}\text { Sociedad administradora de inversiones } \\
\text { y holding. }\end{array}$ \\
\hline Intercorp Financial Services Inc. & Intermediación financiera. \\
\hline $\begin{array}{l}\text { Banco Internacional del Perú S.A.A. } \\
\text { Interbank }\end{array}$ & Operaciones y negocios bancarios. \\
\hline Inteligo Bank Ltd. & Operaciones y negocios bancarios. \\
\hline Inteligo SAB S.A. & Intermediación de valores. \\
\hline Interfondos S.A. & Sociedad Administradora de Fondos. \\
\hline Interfondos SAF & $\begin{array}{l}\text { Administración de fondos mutuos y } \\
\text { fondos de inversión }\end{array}$ \\
\hline Interseguro & $\begin{array}{l}\text { Cía. de Seguros S.A. Cobertura de } \\
\text { seguro y actividades vinculadas al } \\
\text { negocio de seguros. }\end{array}$ \\
\hline URBI Propiedades S.A. & Negocio inmobiliario. \\
\hline Supermercados Peruanos S.A. & $\begin{array}{l}\text { Negocio de representaciones, } \\
\text { comisiones, distribución de bienes y } \\
\text { compra venta de bienes muebles en } \\
\text { general. }\end{array}$ \\
\hline Internacional de Títulos & Sociedad Titulizadora S.A. \\
\hline Intertítulos ST & $\begin{array}{l}\text { Administración de fideicomisos de } \\
\text { titulización. }\end{array}$ \\
\hline Financiera Uno S.A. & $\begin{array}{l}\text { Operaciones y negocios de } \\
\text { financiamiento Inmobiliaria. }\end{array}$ \\
\hline Milenia S.A. & Negocio inmobiliario. \\
\hline InRetail Perú Corp. & $\begin{array}{l}\text { Actividades auxiliares de la } \\
\text { intermediación financiera. }\end{array}$ \\
\hline \multicolumn{2}{|l|}{ Fuente: SMV } \\
\hline
\end{tabular}




\section{CAPÍTULO III: GRUPO DE EMPRESAS}

\section{Marco conceptual}

La actividad empresarial supone la toma de decisiones, principalmente de carácter económico, con el objetivo de aprovechar las oportunidades y desafíos que se presentan y lograr el crecimiento que le permita alcanzar los logros propuestos (incrementar el valor económico). Como se ha señalado, una de las estrategias por las que puede optar una empresa es la de vincularse a otra u otras de igual o diferente rubro, constituyendo lo que se denomina un grupo de empresas (GE).

Se identifica que, entre otras razones, las empresas recurren a la concentración para afrontar, de mejor manera, una crisis económica (casos de empresas familiares); minimizar costos o motivados por el deseo de expansión o como se ha señalado, para eliminar a la competencia.

Sobre la materia, encontramos investigaciones como la de Echaiz Moreno (2009) que señala que no se debe considerar como sinónimos a los conceptos de grupos de sociedades con el de empresas vinculadas, puesto que el último es más amplio, toda vez que las empresas se vinculan de muchas maneras. Una de estas formas es el grupo de sociedades. Señala, que sobre el particular la realidad supera largamente a la normativa, y por esa razón la legislación queda rezagada frente a los fenómenos empresariales, situación a la que no es ajeno nuestro país (p.83).

El concepto de GE tiene distinto origen. En una entrevista realizada para la presente investigación al doctor Jorge Muñiz Sichez (2016), sobre los casos de GE y su aparición en el entorno económico de un país, el citado entrevistado comentó la experiencia internacional, mencionando, en primer lugar, el caso de Italia, cuya experiencia de empresa familiar está basada en congregar a otras del mismo o de diferente rubro, convirtiéndose en toda una institución; tal es el caso de las casas de modas. En Japón, la tradición de los clanes deviene en un estado natural al hablar de grupos empresariales fuertes. En Alemania, es poco frecuente que se llegue a difundir el accionariado entre inversionistas desconocidos; destaca por ello, la unión de los habitantes de una región que fortalecen el vínculo empresarial. En el caso de Estados 
Unidos, en cambio, se impone el accionariado difundido puesto que mayormente, los inversionistas no están unidos por lazos de sangre, ni de ubicación geográfica sino por el afán de lucro. En otras experiencias, como la nuestra, se evidencia una mezcla de estas modalidades (J. Muñiz Sichez, comunicación personal, 11 de enero del 2016).

La importancia de los GE es de tal magnitud que frecuentemente se les asocia con el poder, en todas sus formas, principalmente con el político. "Desde el punto de vista político-jurídico, el grupo no es un fenómeno neutro, en tanto la concentración económica lleva a la concentración de poder y esto se traduce, en muchos casos, en el ejercicio de indebidas influencias sobre las decisiones de los poderes público, en particular por parte de las denominadas, "empresas multinacionales, que no son más que grupos societarios que actúan en varios países a la vez" (como se citó en Favier Dubois y Favier Dubois, s.f., p.10). Asimismo, cuando hay mala fe en su conformación pueden ser causantes de abusos en sus relaciones comerciales.

$\mathrm{Al}$ margen de ello, su influencia en el desarrollo económico nacional es preponderante, porque el éxito de estos también repercute en la sociedad dentro de la cual están inmersos. Ello se aprecia con el aumento de fuentes de trabajo, el aumento en la producción, la creación de nuevos mercados, la adopción de tecnología moderna, el ingreso de una plana gerencial internacional con la cual los nacionales alternan, entre otros. Tampoco se puede dejar de lado, la posibilidad que representa para el país el rol que juegan en la ejecución de los acuerdos comerciales, que abren nuevos destinos para los bienes y servicios que brindan los GE y los efectos positivos que producen en la economía.

\subsection{Definición}

Antes de delimitar y definir el concepto de GE, resulta pertinente señalar que la terminología utilizada contribuye de alguna manera a promover la confusión existente sobre este, más aún porque su actuación en ámbitos diferentes ha de sujetarse a normas sectoriales que delimitan su esencia. En doctrina, se equiparán los conceptos de "grupo de empresas", "grupos de empresarios", "grupo de sociedades", entre otros, resultando, a nuestro juicio, que la noción de grupo de empresas (GE) resulta más amplia y pertinente, por lo cual la mantenemos como referente. 
El profesor Hundskopf, cuando se refiere al grupo de empresas lo define como: uniones de empresas que conservan por sí solas su individualidad o al menos una independencia formal, aunque en determinados casos, no se trate de independencia funcional, y en la que prima una relación de subordinación-dependencia, que se ejerce sometiendo a las mismas a una dirección unificada. (Hundskopf, 1999, p.XVIII).

Una definición de Arce Ortiz (como se citó en Vilcapoma Yuli, 2009) establece que:

El grupo de empresas no es otra cosa que varias empresas, jurídicamente independientes sometidas a una estrategia general común. Esto es, la interrelación de unidades empresariales autónomas en torno a una dirección unitaria, o entendido como un centro múltiple de actividades empresariales. (p.352)

Daniel Echaiz, señala que el GE es:

Un fenómeno derivado de la concentración empresarial, de naturaleza multiarticulada, constituido por dos o más empresas jurídicamente autónomas, en el cual existe una dirección unificada destinada a la satisfacción del interés grupal y para lo cual se establecen relaciones de dominación-dependencia, las que importan el control ejercido por uno o varios sujetos dominantes (pudiendo ser alguna de las sociedades) sobre la empresa o empresas dominadas. (Echaiz, 2002, p. 56).

En nuestra legislación no encontramos norma de rango legal que lo defina. Sí se tienen definiciones en normas de sectores especializados, como el bancario, tributario, bursátil, entre otros.

El sistema jurídico argentino, por ejemplo, no regula específicamente a los GE, sino que "reglamenta algunas consecuencias del control para prevenir algunos de los problemas que éste apareja frente a socios externos y a terceros" (Favier Dubois y Favier Dubois, s.f., p. 19).

\subsection{Características de los GE}

Todo grupo de empresas se caracteriza por la pluralidad, al ser más de dos las empresas con personalidad jurídica que se reúnen, distinta la una de la otra y una de ellas, la dominante, del acuerdo de unión se conforma un interés grupal que guía la gestión empresarial; y, la unidad, que permite al GE actuar como una sola gran empresa frente al mercado y perseguir un objetivo común. Ampliando los conceptos sobre sus características, tenemos: 


\subsubsection{Autonomía jurídica}

Esta característica está vinculada con el concepto de personalidad jurídica, que es la capacidad de ser sujeto de obligaciones y de derechos, lo cual implica asumir una actividad u obligación haciéndose plenamente responsable por ello. En el GE las empresas mantienen intactas sus capacidades, sobre todo frente al mercado, es decir externamente, porque a lo largo del desarrollo empresarial muchas veces ha de ceder a fin de acatar directivas de la empresa dominante. "No existe una correlación entre la pluralidad jurídica de los miembros del grupo con la unidad empresarial (económica, financiera, organizacional) del mismo. El grupo no adquiere personalidad jurídica propia" (Informe Legal Caballero Bustamante, 2009, p.13).

A decir de Echaiz Moreno (2002), la autonomía jurídica se evidencia en que generalmente Las empresas integrantes del grupo:

Conservan su propio objeto, denominación, titular o titulares, plantel de trabajadores, personal administrativo (directores o gerentes), cartera de clientes, cuentas bancarias y titularidad de todo derecho que legal o contractualmente les corresponda (como el de ser mutuataria, arrendadora o comodataria), además de las obligaciones contraídas (bien sean contractuales, laborales, fiscales, societarias o de otra índole). (p.57)

\subsubsection{Relación dominante-dependiente}

Es una característica indispensable para determinar cuándo se está frente a un GE y cuándo no. Se evidencia esta particularidad en la relación existente entre una empresa y la (s) otra (s) y el ejercicio de dominación de la primera sobre la (s) segunda (s). Influencia importante manifestada a través de "cinco elementos que van apareciendo sucesivamente, no temporales: dominación, intensidad, duración, control y dependencia" (Echaiz Moreno, 2002, p. 61).

\subsubsection{Dirección unificada}

Es el factor cohesionador del GE. Sin ella cada empresa planificaría su gestión sin considerar el interés grupal, o estaría en condiciones de rechazar un riesgo que no aprobase como entidad individual o desacataría las directivas para, por ejemplo, 
disponer el reparto de utilidades. En suma, no evidenciar una dirección unificada entre las empresas del grupo es actuar autónomamente. Tal conducta no es propia del GE por cuanto, es la empresa dominante la que impone estrategias comunes, decisiones empresariales, pero siempre identificándose en ellas el interés grupal que persigue el bienestar empresarial del colectivo. Esta característica se materializa con i) medidas de planificación (estrategia empresarial del grupo), ii) medidas de organización (creación de políticas para el desarrollo del grupo), iii) medidas de gestión empresarial (actos administrativos, económicos y financieros).

\subsubsection{Interés grupal}

Es un concepto que incluye múltiples ángulos por cuanto resulta hasta cierto punto, indeterminado. El interés grupal se reconoce en los hechos, se percibe a través del acatamiento de líneas de trabajo empresarial impuestas por la empresa dominante, vale decir, provenientes de una dirección unificada. Estas directrices se basan en el interés grupal que prima sobre el interés de las integrantes del grupo. Esta realidad no está exenta de conflictos; precisamente porque es una empresa, la dominante, la que decidirá lo más conveniente para el grupo, y esto puede que, en muchas oportunidades, vaya en desmedro de los intereses particulares de las demás empresas. A decir de Morales Acosta (1994) "atendiendo el interés grupal se puede llevar a decisiones extremas: como apoyar la supervivencia de una empresa en crisis o simplemente promover la disolución y liquidación de una empresa solvente" (p.29).

\subsubsection{La vinculación económica}

Es otro concepto que es necesario mencionar porque se encuentra ligado al de GE para efectos prácticos y de control. Como lo manifiesta el Estudio Caballero Bustamante (2009) "El grupo de empresas se relaciona de forma inescindible con la vinculación económica empresarial. Criterio asumido para regular de forma conjunta ambas figuras, tal es el caso de las normativas del mercado de valores, sistema financiero y bancario, MYPES, derecho concursal, derecho tributario, contrataciones con el Estado y comercio exterior" (p.11). 


\section{CAPÍTULO IV: PROBLEMÁTICA DE LOS GRUPOS DE EMPRESAS - CUATRO TEMAS RELEVANTES}

El surgimiento de los GE, su desarrollo y la participación en la economía nacional hacen de ellos sujetos de interés para el quehacer jurídico. Entonces, cabe preguntarse, ¿Por qué resulta jurídicamente relevante la problemática de los GE?

En un primer término, se puede afirmar su relevancia por el impacto de su actuación en la sociedad al producir infinidad de relaciones jurídicas, principalmente dentro del campo societario, aunque no exclusivamente. En el caso del derecho societario, el desacuerdo que se presenta entre la legislación propia de las sociedades y la realidad del GE hace que se reclame una normativa que lo delimite, como veremos más adelante.

Así, podemos citar lo que señala el profesor de la Universidad de Madrid, José Cándido Paz, respecto a la necesidad de regulación específica de los GE, para quien la necesidad surge por "el desfase existente entre la estructura del Derecho de sociedades y la realidad organizativa y patrimonial de las sociedades que forman parte de un grupo. El Derecho de sociedades ha sido construido tradicionalmente bajo el modelo de una sociedad independiente, con una voluntad social propia formada en el seno de sus órganos y en persecución de un interés social autónomo. Al introducirse el grupo en este escenario, se producen algunas distorsiones que es necesario reajustar y algunas deficiencias que es necesario suplir. (Paz Ares, 1999, p. 237).

Con la finalidad de profundizar en la realidad de los GE y su ordenación por el Derecho, nos vamos a referir a los siguientes cuatro temas relevantes:

\subsection{El interés grupal del GE frente al interés social de cada empresa}

Una materia que genera controversia en el tratamiento de los GE es el relativo a la preminencia del interés grupal frente al interés social que persigue cada empresa.

En nuestra legislación no encontramos una definición de interés social, y menos aún del interés grupal. En la práctica empresarial se puede observar que, en aras de respaldar el crecimiento del GE, el interés social se puede encontrar eventualmente en 
controversia y hasta quedar relegado frente al interés grupal, y en el extremo verse perjudicado. No se puede dejar de considerar que es el interés grupal el factor de cohesión dentro del GE.

Una de las características que distingue a los GE es la relación de subordinación-dependencia, que se evidencia en el sometimiento de las empresas del grupo a una dirección unificada ejercida por la empresa dominante. A esta corresponde proponer los planes que encaminen las acciones al éxito empresarial del Grupo.

Cabe señalar que es el derecho societario, el regulador de la actuación de la sociedad (empresa), como sujeto principal con personalidad propia y autonomía. En dicha rama del derecho, tácitamente se protege el interés social - pilar del derecho societario - y se le entiende como el interés común de los socios.

Para la doctrina, el denominado interés grupal persigue el conjunto de intereses comunes de los socios, pero lo hace a través del grupo, habida cuenta que el GE no tiene personalidad jurídica, patrimonio individual y estructura orgánica.

Respecto de los efectos del interés grupal, Le Pera, advierte que:

cuando en un grupo de empresas se encuentran los elementos fundamentales: dominio y subordinación, dirección unificada e interés de grupo, se produce un interesante fenómeno, que las empresas implicadas - normalmente una sociedad - dejan de seguir un fin propio para implementarse como instrumento del interés del grupo. (Rodríguez

Chávez, R. (2015, p.60).

En caso de conflicto entre ambos intereses, las empresas del grupo deben preferir al grupal puesto que se trata de un GE por subordinación, por lo que resulta hasta natural la primacía del "interés grupal sobre el interés social".

Nuestra legislación tampoco contempla normas expresas que regulen la responsabilidad por abuso de poder de la empresa dominante frente a las empresas dominadas; aun cuando la razón fundamental para la adopción de las medidas que pueden resultar perjudiciales sea el llamado interés grupal.

En efecto, las sociedades dominantes pueden llegar cometer abusos de poder o perjuicios contra las demás integrantes del grupo, o de sus grupos de interés, ya se trate de sus trabajadores, acreedores, consumidores o de sus accionistas. 
¿Qué actos pueden servirnos de ejemplos de tales medidas? Como respuesta se puede mencionar a aquellas directrices consideradas perjudiciales cuyo acatamiento resulta afectando el patrimonio mismo de las dominadas; también se encuentran aquellas medidas, dispuestas en función de la dirección unificada del GE y que tienen que ver con la facultad de designar o remover a los administradores, con la asignación de créditos, con las políticas de endeudamiento, entre otras.

La pregunta que surge es, ¿frente a abusos del poder o fraude, qué mecanismos de defensa o acciones pueden llevarse a cabo, amparados en la actual legislación?

En primer lugar, se debe señalar que la concepción tradicional de la LGS reconoce la protección al interés social frente a cualquier otro interés. Así tenemos el artículo 139 de la LGS, que dispone que pueden ser impugnados judicialmente los acuerdos de la junta general cuyo contenido sea contrario a la ley, se oponga al estatuto o al pacto social o lesione, en beneficio directo o indirecto de uno o varios accionistas, los intereses de la sociedad...Es para estos casos de conflictos que notamos la ausencia de normas que tengan en cuenta la realidad de los GE, porque al activarse el derecho a impugnar judicialmente el acuerdo, se dejaría de lado el interés grupal para hacer prevalecer el interés social.

A fin de evitar el fraude a la ley y controlar el abuso del derecho, surge como alternativa la figura del "levantamiento del velo societario", entendiéndose por ella, a decir de Le Pera, "que en ciertos supuestos puede prescindirse de la concepción de la sociedad como una persona jurídica independiente, y prestarles adecuada atención a los reales titulares o a los reales intereses que actúan a través de la forma societaria”. (Rodríguez Chávez, R. 2015, p.95). Y considerándolo como una ventaja frente a inequidades o como un mecanismo legal que permite obviar la personalidad jurídica ante casos evidentemente culpables de alterar el normal desenvolvimiento de las relaciones comerciales de los grupos de empresas por daños, perjuicios que a la larga perjudican no solo a la sociedad como tal sino a los accionistas, trabajadores, entre otros.

Respecto a la posibilidad de recurrir a "rasgar" el velo societario, De Trazegnies Granda (2004) considera que esto permite ver más allá de las formas jurídicas a fin de evitar que, detrás de un formalismo jurídico se desarrollen actividades que perjudican a ciertos accionistas de la sociedad o a terceros 
vinculados con algún tipo de contrato. Si bien la autonomía de la persona jurídica tiene que ser respetada como regla general, cuando esas personas jurídicas, se usan para actuar con abuso del derecho y para violentar la auténtica intención de las partes que está constituida por los acuerdos celebrados de grupo a grupo, es preciso penetrar las capas societarias hasta llegar a ese núcleo decisorio donde se forma la verdadera voluntad de las partes.

Quedará pues sujeto a la decisión de los accionistas perjudicados y a la posibilidad de probar el daño ocasionado, recurrir a esta figura, cuyo fundamento jurídico lo encontramos entre los principios del derecho civil referidos a la protección frente al abuso del derecho.

\subsection{Adopción de igual o semejante denominación o razón social}

La realidad que enfrenta un GE al imponer su nombre en el mercado resulta una variable que debe considerar este desde el inicio de sus actividades. La adopción de una misma denominación para las empresas del grupo constituye, si bien una excepción, un derecho que se reconoce al grupo. Ello por cuanto se entiende que la dirección unificada que opera en el GE impone a las empresas conformantes del mismo, la obligación de sujetarse a directivas y estrategias grupales, entre ellas las de marketing, de comunicación, etc., por lo que resulta entendible que deban adoptar una misma denominación que permita su identificación y reconocimiento como integrantes del GE.

Esta denominación similar les permite demostrar su origen y vinculación al Grupo al que pertenecen, así como aprovechar las consecuencias ventajosas de su uso en el mercado para lo cual cuenta con la autorización de la sociedad titular del derecho.

La LGS al plantear una primera norma de protección a la identidad de las personas jurídicas en el artículo $9^{9}$, considera necesario que la denominación o la razón

\footnotetext{
${ }^{9}$ Artículo 9.- Denominación o Razón Social

La sociedad tiene una denominación o una razón social, según corresponda a su forma societaria. En el primer caso puede utilizar, además, un nombre abreviado.

No se puede adoptar una denominación completa o abreviada o una razón social igual o semejante a la de otra sociedad preexistente, salvo cuando se demuestre legitimidad para ello.

Esta prohibición no tiene en cuenta la forma social. No se puede adoptar una denominación completa o abreviada o una razón social que contenga nombres de organismos o instituciones públicas o signos distintivos protegidos por derechos de propiedad industrial o elementos protegidos por derechos de autor, salvo que se demuestre estar legitimado para ello.

El Registro no inscribe a la sociedad que adopta una denominación completa o abreviada o una razón social igual a la de otra sociedad preexistente. En los demás casos previstos en los párrafos anteriores los
} 
social posibilite la identificación de la sociedad como organización distinta a sus titulares o su reconocimiento dentro de determinado sector económico. Por ello exige, dependiendo de su forma societaria:

a) Una denominación social más un nombre abreviado, en los casos de sociedades de responsabilidad limitada. Tal es el caso de la SA (artículos 45 y 284 de la LGS);

b) Una razón social para los casos de sociedades de responsabilidad ilimitada, como son la Sociedad en Comandita, Sociedad Civil, entre otras. Si bien en el citado artículo 9 de la LGS encontramos una restricción en el sentido de que no se puede adoptar una denominación o abreviación o una razón social igual o semejante a otra sociedad ya constituida, registrada y en actividad, se plantea, al mismo tiempo, una excepción que es la que nos interesa para nuestra investigación, porque demuestra el interés de la Ley en proteger el desarrollo de la actividad empresarial, al permitir usar una denominación o razón ya inscrita en el caso que se demuestre legitimidad para ello. ¿Cómo demostrar esa legitimidad? No lo dice. Pero resulta la excepción necesaria para que empresas del mismo grupo adopten una denominación similar que les permitirá el desarrollo de su actividad.

\subsection{Socio minoritario de una empresa conformante de un GE}

Nuestra legislación societaria dispone que los acuerdos en una sociedad, luego de consultar a sus integrantes, se toman con los votos de la mayoría de los accionistas sujetos de derechos y obligaciones en función a su aporte de capital. Los titulares serán socios mayoritarios o minoritarios en función de su aporte, pero se les reconoce derechos por el solo título de accionistas.

Los accionistas minoritarios no detentan el control de la sociedad, porque su principal interés es la rentabilidad de la empresa y el retorno de sus inversiones, es

afectados tienen derecho a demandar la modificación de la denominación o razón social por el proceso sumarísimo ante el juez del domicilio de la sociedad que haya infringido la prohibición.

La razón social puede conservar el nombre del socio separado o fallecido, si el socio separado o los sucesores del socio fallecido consienten en ello. En este último caso, la razón social debe indicar esta circunstancia. Los que no perteneciendo a la sociedad consienten la inclusión de su nombre en la razón social quedan sujetos a responsabilidad solidaria, sin perjuicio de la responsabilidad penal si a ello hubiere lugar. 
decir, tienen un interés estrictamente económico en ella. Cabe señalar la importancia de contar con inversionistas en un mercado en crecimiento.

Frecuentemente, en el entorno de la sociedad, se presenta ante la vorágine de la toma de decisiones comerciales un roce entre los intereses de los integrantes.

Muchas veces serán los accionistas minoritarios los que resultan afectados ante medidas adoptadas por los órganos de administración de las sociedades, en los que han sobrepuesto el interés personal sobre el interés social, en claro apoyo a los intereses de los accionistas mayoritarios, al ser en muchos casos designados por estos.

Ante tales circunstancias, no puede soslayarse el importante rol que cumplen los inversionistas como agentes de la economía nacional, por lo que se espera que la legislación cautele sus intereses; para lo cual se debe brindar confianza y seguridad a estos, como pilares para el fomenta de la inversión. La protección jurídica a la empresa en sí no apoya el abuso ni de los llamados accionistas mayoritarios ni de los minoritarios.

Si estos conflictos pueden darse en una empresa unitaria, similar situación puede ser real en los GE, por lo que cabe señalar que, para el caso de confusión de patrimonios, la actual legislación no brinda la protección específica para contrarrestar actuaciones dolosas y proteger al inversionista frente a estas. Se puede entender que ¿la inversión queda sujeta a los dictados de quienes ostentan el poder y lo ejercen más allá de lo permitido en el pacto social?

Lo cierto es que en la legislación societaria no encontramos una norma que permita alegar responsabilidad solidaria dentro del GE, tampoco solicitar el allanamiento de la personalidad jurídica con el fin de que se pueda responsabilizar a los titulares que comprometieron a la sociedad. Estos son los vacíos que se presentan y sobre los que aún hay que trabajar para dotar a los accionistas minoritarios de la protección necesaria a su inversión sin menoscabar los derechos de la mayoría.

\subsection{Derechos laborales de los trabajadores en un GE}

A lo largo de esta investigación se ha afirmado que los grupos de empresas están conformados por personas jurídicas (sociedades y entidades públicas y privadas) así como por personas naturales (empresarios, trabajadores, entre otros). Los trabajares inmersos en un GE comparten los retos, pero también se enfrentan a situaciones que por 
la estructura misma del grupo - compleja y atípica - pueden conllevar a incumplimientos involuntarios (o voluntarios) de la legislación laboral, que, entre otros aspectos, regula la contratación temporal, tercerización e intermediación, beneficios sociales, entre otros. Estas modalidades, que demanda la propia naturaleza de la actividad empresarial, frecuentemente producen entre empleador y trabajador enfrentamientos ante los tribunales de justicia ocasionados por el reconocimiento de derechos laborales.

Como hemos señalado líneas arriba, los GE se distinguen porque sus integrantes al gozar de personería jurídica, mantienen su independencia frente a terceros, además de tener una dirección unificada, con políticas y directivas comunes, emanadas de la empresa dominante. Por ello, frente a un conflicto laboral en alguna de las empresas conformantes, surge la pregunta: Del grupo de empresas, ¿una o todas pueden ser imputadas por el incumplimiento de una obligación que se derive de una acción u omisión para con sus colaboradores?

Este tema es uno de los más discutibles por la dificultad en reconocer a ciencia cierta a los integrantes de la relación laboral en un GE. Lo que está fuera de toda discusión es que el trabajador tiene todo el derecho a identificar con precisión a su empleador a fin de exigirle el cumplimiento de sus obligaciones y responsabilidades como tal.

Tradicionalmente el derecho laboral se estructura bajo la premisa de que el empleador es una empresa unitaria y tradicional, y que la relación laboral se da solo entre un trabajador y un empleador, quien ejerce las atribuciones de su condición; pero la realidad es que las regulaciones de esta disciplina requieren adaptarse y abarcar a la nueva forma de organización corporativa que supone el GE, que define un nuevo marco empresarial, generador de fuentes de trabajo, y con nuevas condiciones para la contratación laboral.

Consideremos en primer lugar la situación del trabajador de un GE que en los hechos presta servicios a más de una empresa de dicho GE. Esta situación constituye un reto para el régimen tuitivo del derecho laboral, puesto que, al no contar con legislación especial, puede devenir en conflictos, en desprotección o en situaciones de inseguridad jurídica para ambas partes. 
El profesor Lora Álvarez (2011) comentando sobre esta materia formula las siguientes interrogantes: “ ¿Cuál es el empleador del trabajador si este presta servicios a más de una empresa del mismo grupo? ¿Quién asume el pago de sus beneficios?" (párr. 2).

La doctrina y la jurisprudencia han profundizado en la problemática vinculada tratando de encontrar respuestas no halladas en la legislación. Así se ha considerado "a la insolvencia de los integrantes del grupo y las consecuencias económicas negativas que ello puede generar para el trabajador". Por ello, a fin de brindar la tutela efectiva de los derechos del trabajador, "se buscan mecanismos e instrumentos para involucrar patrimonialmente a todo el grupo por las deudas laborales de uno de sus miembros" (Castello, 2007, p. 163).

Dada su trascendencia, la situación laboral del trabajador de un GE ha sido materia de evaluación por el Pleno Jurisdiccional Nacional Laboral, celebrado en el 2008, el que aprobó que "Existe solidaridad en las obligaciones laborales no solamente cuando se configuran los supuestos previstos en el artículo 1183 del Código Civil sino, además, en los casos en los que exista vinculación económica, grupo de empresas o se evidencie la existencia de fraude con el objeto de burlar los derechos laborales de los trabajadores".

El Portal Capital Humano menciona como casos frecuentes de fraudes en los grupos de empresas conformados ficticiamente, a los siguientes: i) limitar el tiempo de servicios para disminuir el monto de la indemnización por despido arbitrario, ii) no alcanzar el tiempo máximo de prestación de servicios para los contratos de trabajo sujetos a modalidad (tiempo máximo que generaría que el contrato de trabajo pase a ser uno a plazo indeterminado), iii) la suma de las jornadas cuando la relación laboral se mantiene de manera simultánea con más de una empresa de un mismo grupo), entre otras (De las Casas y Portal, 2011, p.1).

Jurisprudencialmente, como se ha señalado, y doctrinariamente se reconoce, entonces, la solidaridad en las obligaciones laborales. Y se hace hincapié en que la conformación de un Grupo:

no implica que se usa a este para evadir el cumplimiento de beneficios laborales (vía simulación o fraude)... al presentarse un desconocimiento de los derechos laborales existirá solidaridad, como, por ejemplo, en el pago de beneficios sociales, o que el 
trabajador puede ser considerado trabajador de otra de las empresas del grupo o de todas. (Toyama Miyagusuku, 2011).

El Tribunal Constitucional se ha pronunciado también sobre el tema. Así, en el Expediente $\mathrm{N}^{\mathrm{o}}$ 6322-2007-PA/TC, sobre el recurso de agravio constitucional interpuesto por la empresa Energy Services SA contra la Resolución de la Sala de Derecho Constitucional y Social de la Corte Suprema de Justicia, señaló, a fines del año 2008, ratificando implícitamente el sentido de la resolución objetada, que las empresas de un mismo grupo económico son responsables del pago de adeudos laborales generados por una de ellas.

En sede judicial también existen casos puntuales, y entre ellos destacamos una de las sentencias considerada emblemática por sus repercusiones, la cual se emitió al resolver el recurso de casación, interpuesto por dos empresas que no se calificaban como parte de un mismo grupo económico para efectos de cumplimientos laborales (Telefónica del Perú Sociedad Anónima Abierta y Telefónica Servicios Comerciales Sociedad Anónima Cerrada); nos referimos a la Sentencia $N^{\circ}$ 3969-2009-La Libertad, la cual ha establecido los elementos que sirven para identificar a un grupo económico: 1) Participación activa de un mismo funcionario en dos empresas; 2) Mismo domicilio social para las dos empresas; 3) Diversos anuncios periodísticos que presentan las empresas como parte de un mismo grupo económico. Dichos elementos sirven para los casos que se pueden presentar aun cuando en aplicación del principio de primacía de la realidad, los hechos primarán sobre los documentos.

No obstante, el ejercicio jurisdiccional no es suficiente. En cuanto a la actuación de los jueces frente a casos promovidos por los trabajadores, Vilcapoma Yuli (2009) señala que "La labor de la jurisprudencia es fundamental en estas circunstancias y va desarrollando un rol importante, aunque no por ello disminuye la necesidad imperiosa de una regulación legislativa [cursivas añadidas]" (p. 355). Añadiríamos que esa regulación resultaría predictible, general y libre del arbitrio del juez.

La ausencia de tratamiento legislativo, y por consiguiente de una definición de GE, ocasiona que los operadores de justicia no distingan entre grupo económico, grupo de empresas o empresas con vinculación económica, como si lo hacen las normas sectoriales del mercado de valores, tributarias, entre otras. 
Resulta pertinente señalar que esta preocupación por definir al GE para efectos laborales no es nueva. En el ámbito legislativo se ha evaluado la importancia de contar con una definición de GE, durante la discusión del aún proyecto de Ley General del Trabajo $^{10}$ que introdujo en su articulado una definición de grupo de empresas. Cabe precisar que el proyecto no ha sido debatido aún en el Pleno del Congreso.

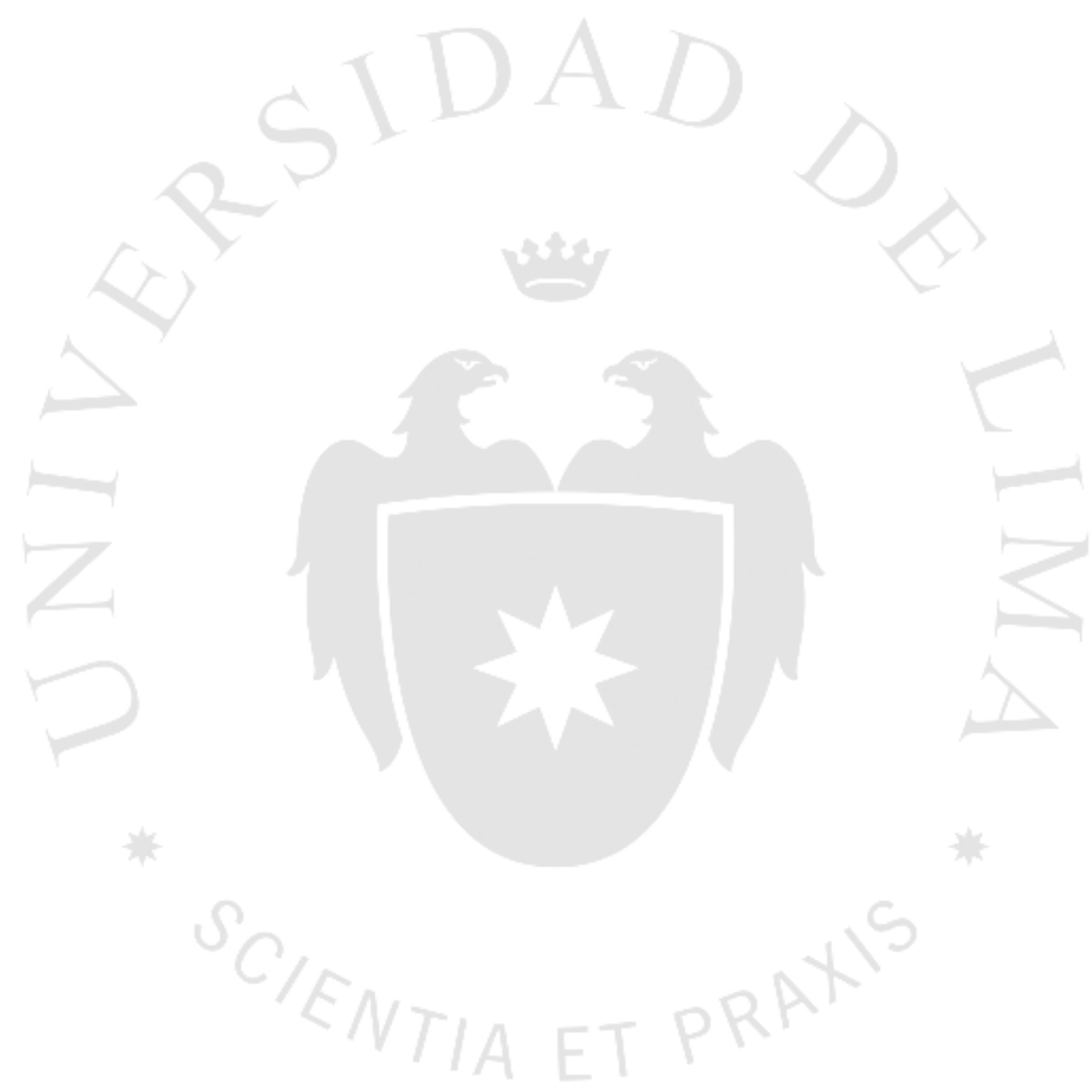

\footnotetext{
${ }^{10}$ Proyecto de Ley 138-2011-CR
} 


\section{CAPÍTULO V: ANÁLISIS SOBRE LA NECESIDAD DE APROBAR LA LEY SOBRE GRUPOS DE EMPRESAS}

En este capítulo nos proponemos analizar, en primer lugar, las leyes y los reglamentos que rigen las actividades de los GE, cuyo conjunto constituye asimismo el contenido de una futura norma de rango legal que incorpore en un solo cuerpo legal, esta materia específica.

\subsection{Constitucionalidad de la iniciativa}

La Constitución Política del Perú en su Capítulo Régimen Económico establece el respeto a la libre iniciativa privada, la misma que se ejerce en una economía social de mercado (artículo 58). Asimismo, se impone al Estado el respeto y la obligación de garantizar, entre otros, la libertad de empresa, comercio e industria (artículo 59). Además, el Estado, al reconocer el pluralismo económico, reconoce también que la economía nacional se sustenta en la coexistencia de diversas formas de propiedad y de empresa (artículo 60). Por lo tanto, el Estado debe brindar las garantías necesarias para que la actuación de las empresas se desenvuelva dentro de un ámbito de transparencia, predictibilidad y respeto por los derechos y obligaciones que les corresponda, todo lo cual debe contribuir a la seguridad jurídica de las propias empresas y los grupos de interés, así como de los inversionistas y de la sociedad.

\subsection{Marco legal vigente vinculado con los GE}

A continuación, se señalan las normas que se vinculan con el objeto de esta investigación, divididas por ámbitos de aplicación. Sobre ellas, puede decirse, en términos generales, que cubren algunos aspectos, pero no dan un tratamiento integral al tema de los GE.

\subsubsection{Los grupos de empresas en el derecho societario}


a) La Ley General de Sociedades no regula específicamente a los grupos empresariales. En el artículo 105 se refiere, por única vez y de forma indirecta, a los grupos de sociedades, sin definirlos:

Artículo 105. Control indirecto de acciones

Las acciones de propiedad de una sociedad que es controlada por la sociedad emisora de tales acciones no dan a su titular derecho de voto ni se computan para formar quórum. Se entiende por sociedad controlada aquella en la que, directa o indirectamente, la propiedad de más del cincuenta por ciento de acciones con derecho a voto o el derecho a elegir a la mayoría de los miembros del directorio corresponda a la sociedad emisora de las acciones.

La disposición citada menciona a la sociedad controlada, a la sociedad emisora, y al elemento de control entre estas. Considera una forma de vigilar abusos e incluir limitaciones al derecho de voto. En su análisis sobre este artículo, Elías Laroza (2000) sostiene que para desanimar actitudes fraudulentas

La norma establece que las acciones de propiedad de una sociedad que se encuentra bajo control de la sociedad emisora de tales acciones no dan a su titular derecho a voto ni se computan para el quórum. De tal manera que se produce la suspensión de los derechos de las acciones, al estar en poder de las subsidiarias controladas por la propia emisora. (p. 213)

En cambio, para Daniel Echaiz, esta norma en primer lugar:

contiene una denominación equivocada porque no se da el caso de una dominación indirecta sino ante dos relaciones de dominación directa (la sociedad A domina a la sociedad B y la sociedad B domina a la sociedad A). Va más allá del contenido de la sumilla y enfrenta la disyuntiva de si es suficiente, en el propósito de proteger a los inversionistas minoritarios de un grupo de empresas, la proscripción del derecho de voto y sus efectos sobre el quórum o si se requieren otras medidas. (Echaiz, 2009, p.22).

En este punto, consideramos que de legislarse la materia de modo integral la protección al socio minoritario de una empresa integrante del grupo ha de constituir un tema de gran importancia, pues está en juego también la continuidad de la propia empresa. 
b) La LGS en el artículo 11, regula el objeto social. A los efectos de esta investigación, interesa analizar la posibilidad de que se presenten casos que la doctrina denomina "actos ultra vires" y sus efectos dentro del GE.

Previamente, conviene considerar si: ¿Es un acto ultra vires, cualquier acto de la sociedad que salga del marco del objeto social? Y, por lo tanto, ¿se encuentra fuera de la competencia de la sociedad y no es responsable de ello?

El profesor Elías Laroza (1995) define a los actos ultra vires como "aquellos que realizan los apoderados de una sociedad mercantil y que no están contemplados expresamente en el objeto social"' (p. 87).

Por tanto, los administradores con poder suficiente, según el artículo 12 de la LGS al ratificar una operación o negocio que va más allá del objeto social, obligan a la sociedad.

No sucede así en otras realidades, tales como la anglosajona, que desconoce tal responsabilidad para la entidad. Consecuentemente, "la empresa no puede argumentar la nulidad de los mismos frente a terceros, ni mucho menos exceptuarse de responsabilidad frente estos últimos” (Elías Laroza 1995, p.89). Será de responsabilidad del contratante la verificación de los poderes con que actúa el representante.

Nuestra legislación societaria, por tanto, brinda protección a los contratantes y a los terceros de buena fe, al admitir implícitamente la validez de los actos ultra vires. Ello cobra significativa importancia en la actividad de los GE, la cual se caracteriza por su dinamismo y flexibilidad.

Dado que oportunidades de negocio no pueden ser dejadas de lado, la citada protección evita los conflictos que estas decisiones podrían generarse.

Dentro de la sociedad, en caso de daño, se podría recurrir a los artículos 177 y 178 de la LGS, que disponen que los directores responden limitada y solidariamente ante la sociedad, los accionistas y los terceros por los daños y perjuicios ocasionados por acuerdos contrarios al estatuto. Está eximido de esta responsabilidad el miembro que hubiese manifestado su disconformidad en el momento oportuno (constando ello en acta o por carta notarial). Queda subsistente el derecho a impugnar los efectos del acuerdo. 
Dentro de este contexto, los GE al ir más allá del objeto social, anteponen el interés grupal al social. Pero este, agregado no se encuentra claramente regulad en nuestra legislación societaria y ha de ser materia de estudio y debate en la propuesta legislativa que se formule.

\subsubsection{Los grupos de empresas en el derecho de mercado de valores}

El Reglamento de Propiedad Indirecta, Vinculación y Grupos Económicos. Resolución de Superintendencia N 00019-2015-SMV/01 (Publicado el 18/09/2015 y que entrará en vigencia el 01.01.17), define GE como:

- Grupo económico (artículo $7^{\circ}$ ): Grupo Económico es el conjunto de entidades, nacionales o extranjeras, conformadas por al menos dos entidades, cuando alguna de ellas ejerce el control sobre la o las demás o cuando el control sobre las entidades corresponde a una o varias personas naturales que actúan como unidad de decisión. Las personas naturales no forman parte del grupo económico.

- Control (artículo $6^{\circ}$ ): Se denomina control a la influencia preponderante y continua en la toma de decisiones de los órganos de gobierno de una persona jurídica u órganos que cumplan la misma finalidad en el caso de un ente jurídico.

Este Reglamento es de aplicación a aquellas sociedades que se encuentran supervisadas y reguladas a través de la SMV. Esta norma tiene carácter sectorial. Fue expedida en virtud a la obligación que la Superintendencia del Mercado de Valores tiene, de acuerdo con su Ley Orgánica, de proteger al inversionista, a la eficiencia y a la transparencia de los mercados que supervisa. Sus disposiciones sobre definición y requerimientos de información, aplicables a los GE, han sido actualizadas a fin de armonizarlas con las de la Superintendencia de Banca, Seguros y AFP (SBS). Además, el citado Reglamento responde al importante aumento de los actores que participan en el mercado de valores y que presentan en su composición orgánica, estructuras complejas propias de la actividad empresarial actual.

Para poder resolver la casuística que se presenta, y ante la ausencia de norma específica, jurisprudencialmente se recurre a su contenido para cubrir algunos vacíos, aunque de manera limitada. Así se aprecia en diferentes sentencias casatorias, las cuales se remiten a sus definiciones para acreditar la presencia del GE.

\subsubsection{Los grupos de empresas en el derecho bancario y financiero}


La Resolución SBS 5780-2015, que Aprueba nuevas Normas Especiales sobre Vinculación y Grupo Económico y deroga la Resolución SBS N 445-2000, define al GE:

Artículo $8^{\circ}$. - Definición de grupo económico

Entiéndase por grupo económico al conjunto de personas jurídicas y/o entes jurídicos, nacionales o extranjeros, conformado al menos por dos integrantes, cuando alguno de ellos ejerce control sobre el otro u otros, o cuando el control sobre las personas jurídicas y/o entes jurídicos corresponde a una o varias personas naturales que actúan de manera conjunta como una unidad de decisión. Los grupos económicos se clasifican en conglomerado financiero, conglomerado mixto y conglomerado no financiero.

Control (artículo $9^{\circ}$ ): Se denomina control a la influencia preponderante y continua en la toma de decisiones de los órganos de gobierno de una persona jurídica u órganos que cumplan la misma finalidad en el caso de un ente jurídico. (...)"

Es de aplicación a las instituciones financieras que operan bajo la Ley del sistema financiero. Es una norma de carácter sectorial que aporta criterios sobre vinculación y conformación de grupos económicos, busca precisar las materias de acuerdo a los estándares internacionales de los que nuestro país no puede quedar al margen. Debe señalarse que presenta similitud en los conceptos que encontramos en el Reglamento de Propiedad Indirecta, Vinculación y Grupos Económicos. Resolución de Superintendencia $N^{\circ}$ 00019-2015-SMV/01- publicado con posterioridad - con la idea de unificar definiciones y ejercer un mejor control y supervisión.

En definitiva, se trata de una norma dictada en contextos especiales y con propósitos específicos para la SBS es importante la definición de GE porque le permite elaborar información más confiable sobre el nivel de riesgo de las colocaciones de las entidades del sistema financiero" (Muñoz Salgado, 2008).

\subsubsection{Los grupos de empresas en el derecho tributario}

La Ley del Impuesto General a las Ventas e Impuesto Selectivo al Consumo, cuyo Texto Único Ordenado fue aprobado por Decreto Supremo $N^{\circ} 055-99-\mathrm{EF}$, contiene las siguientes disposiciones. Asimismo, el artículo 32, inciso b) del DS 179-2004-EF TUO de la Ley del Impuesto a la Renta. 
- Sujetos del impuesto (Artículo 53, a): Son sujetos del impuesto en calidad de contribuyentes: a) Los productores o las empresas vinculadas económicamente a éstos, en las ventas realizadas en el país;

-Empresas vinculadas económicamente (Artículo 57): Las empresas que vendan bienes adquiridos de productores o importadores con los que guarden vinculación económica, sin perjuicio de lo pagado por éstos, quedan obligados al pago del Impuesto Selectivo al Consumo con la tasa que por dichas ventas corresponda al productor o importador vinculado. (...)

El derecho tributario necesita identificar con precisión a los sujetos obligados a fin de que respondan por sus obligaciones tributarias frente al fisco. Además, requiere que quede expresamente contemplado en la legislación en atención al Principio de Legalidad exigido en materia tributaria ${ }^{11}$.

La doctrina reconoce que respecto de la determinación del concepto de GE:

En el ámbito del Derecho tributario también generan interés y preocupación, el interés se centra en los efectos distorsivos que puede tener el grupo de empresas en la configuración de los impuestos ya que pueden utilizarse como herramientas o vehículos para evadir tributos u obtener ventajas indebidas. Por otro lado, el agrupamiento de empresas puede tener como consecuencia la insolvencia de algunas de sus unidades, con la consiguiente pérdida de ingresos fiscales. (Castello, 2007, p.163)

\subsubsection{Los grupos de empresas en la legislación referida a MYPES}

${ }^{11}$ Así lo dispone la Norma IV del Título Preliminar del Código Tributario que señala:

\section{NORMA IV: PRINCIPIO DE LEGALIDAD - RESERVA DE LA LEY}

Sólo por Ley o por Decreto Legislativo, en caso de delegación, se puede:

a) Crear, modificar y suprimir tributos; señalar el hecho generador de la obligación tributaria, la base para su cálculo y la alícuota; el acreedor tributario; el deudor tributario y el agente de retención o percepción, sin perjuicio de lo establecido en el Artículo $10^{\circ}$;

b) Conceder exoneraciones y otros beneficios tributarios;

c) Normar los procedimientos jurisdiccionales, así como los administrativos en cuanto a derechos o garantías del deudor tributario;

d) Definir las infracciones y establecer sanciones;

e) Establecer privilegios, preferencias y garantías para la deuda tributaria; y,

f) Normar formas de extinción de la obligación tributaria distintas a las establecidas en este Código. Los Gobiernos Locales, mediante Ordenanza, pueden crear, modificar y suprimir sus contribuciones, arbitrios, derechos y licencias o exonerar de ellos, dentro de su jurisdicción y con los límites que señala la Ley.

Por Decreto Supremo refrendado por el Ministro del Sector competente y el Ministro de Economía y Finanzas, se fija la cuantía de las tasas.

En los casos en que la Administración Tributaria se encuentra facultada para actuar discrecionalmente optará por la decisión administrativa que considere más conveniente para el interés público, dentro del marco que establece la ley. 
El Decreto Legislativo 1086, que aprueba la Ley de Promoción de la Competitividad, Formalización y Desarrollo de la Micro y Pequeña Empresa y del Acceso al Empleo Decente, considera en su Reglamento, aprobado por el Decreto Supremo No 008-2008TR, en el artículo $4^{12}$, al grupo económico como: “el conjunto de empresas, cualquiera sea su actividad u objeto social, que están sujetas al control de una misma persona natural o jurídica o de un mismo conjunto de personas naturales o jurídicas ".

Lamentablemente, "la definición no presta gran ayuda al campo laboral puesto que, si bien señala los porcentajes de participación accionarial, de capital, etc., para concretar la figura del grupo de empresas; no aclara el gran problema de la definición misma de grupo de empresas y su consecuencia jurídica, ni de quién sería el empleador bajo esta definición" (Vilcapoma Yuli, 2009, p.353). Y esto supone una complicación para el operador jurídico, por cuanto es en este sector donde se presentan condiciones de trabajo precario. Además, no se facilitaría el cumplimiento de una de las finalidades de la citada ley que es regular el acceso al empleo decente en este tipo de empresas.

\subsection{Proyectos de Ley en el Congreso de la República}

\footnotetext{
${ }^{12}$ D.S. N ${ }^{\circ}$ 008-2008-TR. Reglamento del Texto Único Ordenado de la Ley de Promoción de la Competitividad, Formalización y Desarrollo de la Micro y Pequeña Empresa y del Acceso al Empleo Decente - Reglamento de la Ley MYPE Artículo 4.- GRUPO ECONÓMICO Y VINCULACIÓN ECONÓMICA Se considera como grupo económico al conjunto de empresas, cualquiera sea su actividad u objeto social, que están sujetas al control de una misma persona natural o jurídica o de un mismo conjunto de personas naturales o jurídicas. Configurado el grupo económico, éste se mantendrá mientras continúe el control a que se refiere el párrafo anterior. Se considera que dos (2) o más empresas tienen vinculación económica cuando: 1 . Una persona natural o jurídica posea más de treinta por ciento $(30 \%)$ del capital de otra persona jurídica, directamente o por intermedio de un tercero. 2. Más del treinta por ciento $(30 \%)$ del capital de dos (2) o más personas jurídicas pertenezca a una misma persona natural o jurídica, directamente o por intermedio de un tercero. 3. En cualquiera de los casos anteriores, cuando la indicada proporción del capital pertenezca a cónyuges o convivientes entre sí o a personas naturales vinculadas hasta el segundo grado de consanguinidad o afinidad. 4. El capital de dos (2) o más personas jurídicas pertenezca en más del treinta por ciento (30\%) a socios comunes a éstas. 5. Cuando las personas naturales titulares de negocios unipersonales son cónyuges, convivientes o parientes hasta el segundo grado de consanguinidad o afinidad y cuenten con más del veinticinco por ciento $(25 \%)$ de trabajadores en común. 6. Las personas jurídicas o entidades cuenten con uno o más directores, gerentes, administradores u otros directivos comunes, que tengan poder de decisión en los acuerdos financieros, operativos o comerciales que se adopten. 7. Una empresa no domiciliada tenga uno o más establecimientos permanentes en el país, en cuyo caso existirá vinculación entre la empresa no domiciliada y cada uno de sus establecimientos permanentes y entre todos ellos entre sí. 8. Una empresa venda a una misma empresa o a empresas vinculadas entre sí, el ochenta por ciento (80\%) o más de sus ventas. 9. Una misma garantía respalde las obligaciones de dos empresas, o cuando más del cincuenta por ciento $(50 \%)$ de las de una de ellas son garantizadas por la otra, y esta otra no es empresa del sistema financiero. 10. Más del cincuenta por ciento $(50 \%)$ de las obligaciones de una persona jurídica sean acreencias de la otra, y esta otra no sea empresa del sistema financiero. La vinculación quedará configurada cuando se produzca la causal y regirá mientras ésta subsista. Los supuestos de vinculación señalados anteriormente no operarán con empresas pertenecientes a la actividad empresarial del Estado. En caso el MTPE determine la existencia de un grupo económico o vinculación económica entre micro y pequeñas empresas, excluirá dichas empresas de los alcances de la Ley cuando corresponda.
} 
En el Poder Legislativo se pretendió aprobar una ley que permita determinar cuándo nos encontramos frente a un grupo de empresas, pero el contenido de la propuesta no satisfizo la evaluación de la comisión dictaminadora por cuanto esta consideró que las normas dispositivas carecían de responsabilidades u obligaciones respecto de los sujetos, sean personas naturales o jurídicas vinculadas a un GE. En tal sentido, no alcanzó un mínimo de apoyo a fin de continuar con el trámite legislativo hasta convertirse en ley de la República.

Nos referimos al Proyecto de Ley 1320-2012-CR, que propone establecer los casos en los cuales se considera la existencia de propiedad indirecta, vinculación y grupos económicos. La iniciativa es de autoría del Grupo Nacionalista, a propuesta del congresista Tomás Zamudio. Ingresó a Trámite Documentario el 09-07-12 y fue enviado a la Comisión de Justicia y Derechos Humanos a fin de que sea estudiado y dictaminado por dicho grupo.

a) Contenido del Proyecto de Ley.

Mediante el citado proyecto se propone determinar los casos en los cuales se produce la propiedad indirecta, vinculación y grupos económicos. Brinda la definición de propiedad indirecta y la forma en que esta se computa. También propone la definición de vinculación, de control y de grupos económicos ${ }^{13}$.

En la exposición de motivos del proyecto se señala como fundamento de la propuesta, la Resolución 90/2005/EF/94.10 referida a normas especiales sobre vinculación, control y grupos económicos. En cuanto al alcance de la norma actual, sostiene el autor que se trata de una de carácter interno que no vincula a otras áreas del derecho ni es de obligatorio cumplimiento por la judicatura. Por lo tanto, concluyen que resulta de impostergable necesidad regular esta realidad empresarial a fin de evitar fraudes a la ley por la desvinculación que se puede dar al asumir responsabilidades laborales, civiles, tributarias, entre otras. Las mismas que se frenarían al aprobarse esta norma.

b) Dictamen de la Comisión de Justicia y Derechos Humanos del Congreso de la República.

\footnotetext{
${ }^{13}$ PL 1320-2012-CR. Ver en http://www.congreso.gob.pe/proyectosdeley/
} 
La Comisión de Justicia y Derechos Humanos, luego de evaluar el proyecto de ley materia de comentario, sostuvo que "definir los conceptos de propiedad indirecta, vinculación y grupos económicos, sin establecer las obligaciones o las responsabilidades que ello genere, ni establecer los ámbitos en los que aplicará la mencionada ley, abstrayéndolo del ámbito bursátil para generalizarlo, significaría imponer a las personas naturales propietarias de bienes, acciones, participaciones, etc., obligaciones o responsabilidades que podría significar una contravención a sus derechos constitucionales como el derecho de propiedad, de libertad de contratación, libertad de participación en la vida económica del país, de libre iniciativa privada, de libertad de empresa o a la inviolabilidad de la propiedad" (Dictamen de la Comisión de Justicia y DDHH, 2015, p.1).

A fin de sustentar el dictamen, se enfatiza que "estas definiciones deben ser consignadas de manera especial y específica en las legislaciones sectoriales pertinentes como es el caso, por ejemplo, respecto al Impuesto Selectivo al Consumo o al Impuesto a la Renta...” (Id). Finalmente, recomienda por mayoría, la NO APROBACIÓN del citado proyecto.

Cabe precisar que por disposición del Reglamento del Congreso de la República (Artículo 78, segundo párrafo) ${ }^{14}$, si la proposición de ley es rechazada el Presidente ordena su archivo. Y no podría ingresar a trámite la misma u otra que trate el mismo tema hasta el siguiente periodo anual de sesiones. Pero esta disposición contiene una excepción, y es que la mitad más uno del número legal de congresistas puede acordar lo contrario.

\subsection{Reflexiones sobre la dación de una ley sobre grupos de empresas}

¿Hasta qué punto el derecho debe armonizar las relaciones económicas sin que ello signifique una valla para el desarrollo de estas? ¿El derecho como conjunto de

\footnotetext{
${ }^{14}$ Debate y aprobación

Artículo 78.- (...)

Si la proposición de ley o resolución legislativa es rechazada, el Presidente ordenará su archivo. No podrá presentarse la misma proposición u otra que verse sobre idéntica materia hasta el siguiente periodo anual de sesiones, salvo que lo acuerde la mitad más uno del número legal de Congresistas. (..)
} 
relaciones normadas debe intervenir a fin de materializar en una norma, doctrina o jurisprudencia los cambios que observamos en la actividad empresarial?

No es materia de esta investigación llegar al nivel de detalle que dé cuenta de los beneficios o de los costos que implica contar o no con una norma jurídica. Es importante que el Estado brinde señales claras para que el país sea predictible, cuente con seguridad jurídica y que sea atractivo a las inversiones. Todo ello, dentro de un marco de protección a los derechos humanos, laborales y todos los que se vinculen con las personas, entidades y actividades empresariales.

Legislar es el acto de hacer leyes. Se espera que estas sean buenas leyes, esto significa que, con independencia de la forma correcta, el contenido ha de expresar la preocupación sobre un problema que necesita regulación, para fomentar la paz social y cuyo análisis del costo de ignorarlo así lo recomienda. Así también, legislar es acoger en una ley las mejores experiencias y soluciones que se adaptan a una realidad social, económica, materializando acciones con carácter imperativo y de obligatorio cumplimiento.

En el campo del derecho empresarial, la participación del derecho - sea ésta a través de una ley o de la doctrina - en la conformación de grupos de empresas, debe darse, como se sostiene, en doctrina, al advertir que estos

Interesan al Derecho en general, ya que su funcionamiento puede afectar tanto intereses generales como particulares o individuales, como sucede con la formación de monopolios y oligopolios que tienden a distorsionar la competencia y los precios en el mercado y a disminuir el poder político de los Estados... los grupos de empresas... en sí mismos no son ni buenos ni malos, pero debido a los efectos que genera su actuación y la complejidad jurídica de los problemas que se crean, resulta imprescindible estudiar y regular los mismos desde la perspectiva de un verdadero Derecho de grupos, necesariamente interdisciplinario. (Castello, 2007, p.163).

La ausencia de una regulación positiva sobre los GE puede provocar en determinados casos, la generación de conflictos en la sociedad, principalmente, sociales y económicos, y que suelen manifestarse en demandas, denuncias y reclamos en sede jurisdiccional o en la interrupción de las actividades comerciales que requiere el país.

Por todo ello, consideramos que, si se opta por regular esta materia, ello coadyuvaría a que los titulares, accionistas, administradores y representantes de los GE 
se desempeñen en un marco de transparencia y de cumplimiento de normas imperativas. Dichas herramientas legales han de tener carácter multisectorial, de modo que se integren los ámbitos con conceptos claros y prácticos. La predictibilidad del concepto jurídico empresarial, redundará en la protección constitucional que debe brindar el Estado a los emprendimientos dentro del marco de la libertad de empresa, a sus accionistas y a la economía nacional, en último término.

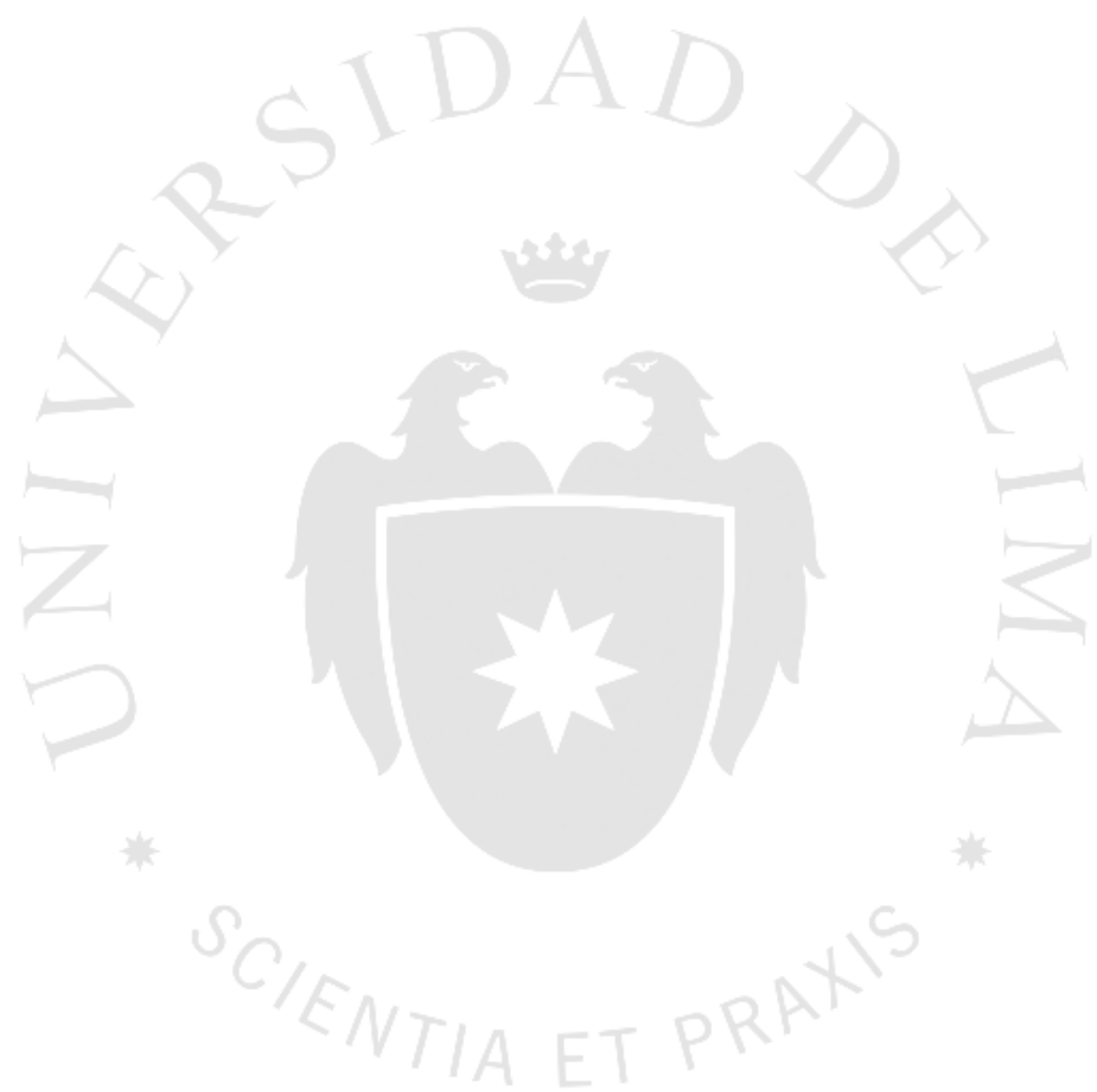




\section{CONCLUSIONES}

- La evolución de la economía a través de la acumulación de capital y la reorganización de las empresas hacia nuevas formas de gestión y producción permiten afirmar que los GE constituyen hoy en día un prototipo de organización empresarial que se encuentra en pleno desarrollo.

- Los GE representan un fenómeno que ha "roto los moldes" tradicionales de hacer empresa y son fomentados por la innovación, las nuevas tecnologías, la información y los nuevos mercados.

- Los GE - como manifestación económica diferente al tradicional concepto de empresa unitaria - adoptan una estructura orgánica, compleja y multidisciplinaria lo que ocasiona dificultad en individualizar sus características.

- El Estado debe brindar garantías para que las empresas se desarrollen dentro de un ámbito de transparencia, predictibilidad y así contribuir a la seguridad jurídica de las propias empresas, de sus accionistas, acreedores, trabajadores y de la sociedad.

- El legislador no puede quedar al margen de los fenómenos económicos que nacen del dinamismo empresarial y que por la misma naturaleza del mercado tienden a ser desregulados.

- Se requiere proponer, debatir y aprobar una legislación integral que contenga mínimamente su definición, respeto por los derechos y obligaciones que les corresponda. Así como medidas de promoción y estímulo a la inversión y desanimar conductas contrarias al derecho vigente. 


\section{REFERENCIAS}

Arias-Schreiber Pezet, M. (1994). Los contratos modernos. Lima: Gaceta Jurídica.

Chanamé Orbe, R. (2009). Exégesis de la Constitución económica. Revista Oficial del Poder Judicial, 3(5).

Chanamé Orbe, R. (2015). Constitución económica. Derecho \& Sociedad, (40), 43-63. Recuperado de http://revistas.pucp.edu.pe/index.php/derechoysociedad

Castello, A. (2007). Grupo de empresas: enfoque laboral. Revista do Tribunal Regional do Trabalho da $15^{a}$ Região, (30), 161-182. Recuperado de http://portal.trt15.jus.br/web/biblioteca/revista-eletronica

De las Casas, O. y Portal, A. (14 de abril de 2001). Identificación de empresas vinculadas. Recuperado de http://www.infocapitalhumano.pe/recursoshumanos/alerta-legal/identificacion-de-empresas-vinculadas/

De Trazegnies Granda, F. (septiembre del 2004). El rasgado del velo societario para determinar la competencia dentro del arbitraje. Recuperado de http://macareo.pucp.edu.pe/ftrazeg/aafaa.htm

Diario Gestión 7 de febrero de 2016. Empresas. El 56\% de empresas peruanas realiza fusiones y adquisiciones para obtener activos estratégicos. Diario Gestión. Recuperado de http://gestion.pe/empresas/56-empresas-peruanas-realizafusiones-y-adquisiciones-obtener-activos-estrategicos-2153853

Durand, F. (2013). Socioeconomías informales y delictivas. En W. Jungbluth M. (Comp.), Perú Hoy: el Perú subterráneo (pp. 19-37). Lima: Desco.

Echaiz Moreno, D. (2002). El control en la política empresarial de los grupos de sociedades. Revista Peruana de Derecho de la Empresa, 54, 55-87.

Echaiz Moreno, D. (2009). Radiografía para prevenir una autopsia. Análisis crítico de la Ley General de Sociedades a once años de su vigencia (1998-2009). (Tesis para optar el título de magister en Derecho de la Empresa). PUCP. Perú.

Elías Laroza, E. (1995). Los actos ultra vires en las sociedades anónimas. Revista de Derecho Thémis. 31, 87 -89. Recuperado de http://revistas.pucp.edu.pe/index.php/themis/article/view/11511/12031

Elías Laroza, E. (2000). Derecho societario peruano. Trujillo, Perú: Normas Legales.

Favier Dubois, E. M. y Favier Dubois, E. M. (s.f.). El grupo de sociedades, panorama societario y concursal. Recuperado de http://www.favierduboisspagnolo.com/trabajos_doctrina/GRUPOS_DE_SOCIE DADES.pdf 
Flores Polo, P. (1993). La empresa en la nueva Constitución. Recuperado de http://www.teleley.com/contenlegal.php?idm=2366

Hundskopf Exebio, O. (1998). Regulación Jurídica de los grupos de empresas. Informativo legal Rodrigo, 149, p. XIX.

Hundskopf Exebio, O. (1999), Empresa y sociedad: ¿Por qué grupos de empresas en lugar de grupos de sociedades? Informativo Legal Rodrigo. 152, p.XVIII in fine $-\mathrm{XIX}$.

Informativo Caballero Bustamante. (2009). Revista de Asesoría Especializada. Derecho Corporativo. Los "grupos de empresas" y los supuestos de "vinculación económica" en la legislación peruana (Primera Parte) 1ra. Quincena. Marzo 2009. Los "grupos de empresas" y los supuestos de "vinculación económica" en la legislación peruana (Segunda Parte). 2da. Quincena. Marzo 2009. Los "grupos de empresas" y los supuestos de "vinculación económica" en la Legislación Peruana (Tercera Parte) 1ra. Quincena. Abril 2009.

Kresalja Rosselló, B. (2004). La libertad de empresa: fundamento del sistema económico constitucionalizado. En Libro Homenaje a Jorge Avendaño (pp. 540). Lima: Pontificia Universidad Católica del Perú.

Ley N. ${ }^{\circ}$ 26887, Ley General de Sociedades. (9 de diciembre de 1997). Recuperado del sitio de internet del Sistema Peruano de Información Jurídica:

http://spij.minjus.gob.pe/spij.html

Lora Álvarez, G. (31 de marzo del 2011). Las nuevas relaciones laborales en los grupos empresariales. Recuperado de http://www.esan.edu.pe/conexion/actualidad/2011/03/31/las-nuevas-relacioneslaborales-en-los-grupos-empresariales/

Loayza, N. (2008). Causas y consecuencias de la informalidad en el Perú. Revista Estudios Económicos, (15), 43-64. Recuperado de http://www.bcrp.gob.pe/docs/Publicaciones/Revista-EstudiosEconomicos/15/Estudios-Economicos-15-3.pdf

Matos Mar, J. (1985). Desborde popular y crisis del estado. Lima: Instituto de Estudios Peruanos.

Morales Acosta, A. (1994). Los grupos de sociedades. Advocatus, (6). p.24-32.

Muñoz Salgado, S. M. (marzo de 2008). El concepto de vinculación en la "participación eh la administración" y por el "control" para efectos de la normativa de precios de transferencia. Revista (46), 153-176. Recuperado de http://www.ipdt.org/publicaciones/detalle/71

Paz-Ares, C. (1999). Uniones de empresas y grupos de sociedades. Revista jurídica Universidad Autónoma de Madrid, (1), 223-253. Recuperado de https://repositorio.uam.es/handle/10486/3023

Rodríguez Chávez, R. (2015). El interés social y el interés grupal en los grupos de empresas por subordinación: tutela del interés social de las sociedades 
dominadas. (Tesis para optar el grado de Magíster en Derecho de la Empresa). PUCP. Perú.

Strandberg, L. (marzo del 2010). El compromiso con los grupos de interés. Cuadernos de la Cátedra "La Caixa" de Responsabilidad Social de la Empresa y Gobierno Corporativo, (10). Recuperado de http://www.iese.edu/es/files/Cuaderno\%20No\%2010 tcm5-61597.pdf

Toyama Miyagusuku, J. (segunda quincena de marzo del 2011). Informativo Laboral Miranda \& Amado, (7).

Vilcapoma Yuli, T. (marzo del 2009). La responsabilidad solidaria en los grupos de empresas. RAE Jurisprudencia: Revista de Análisis Especializado de Jurisprudencia, 1(9), 349-365.

Villanueva Haro, B. (2007). La concentración y concertación empresarial en los planos de lo positivo, difuso y negativo. Derecho y Cambio Social, (10). Recuperado de http://www.derechoycambiosocial.com/index.htm 


\section{BIBLIOGRAFÍA}

Galluccio, G. y Mori, P. (2012). La extensión del convenio arbitral a los grupos de sociedades. Lima: Ius et Veritas.

Hernández Bejarano, M. (2013). Definición laboral de grupo de empresa y el carácter excepcional de su condición como empleador. Temas Laborales, (119), 261-271.

Kresalja Rosselló, B. y Ochoa, C. (2009). Derecho constitucional económico. Lima: Pontificia Universidad Católica del Perú.

Toledo Toribio, O. (10 de marzo del 2009). Responsabilidad solidaria en el cumplimiento de las obligaciones laborales [mensaje en un blog]. Recuperado de http://omartoledotoribio.blogspot.pe/2009/03/responsabilidad-solidaria-enel.html 